\title{
Prefrontal Cortex Dysfunction in Fragile X Mice Depends on the Continued Absence of Fragile X Mental Retardation Protein in the Adult Brain
}

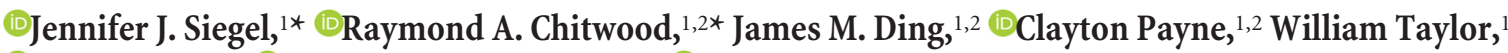 \\ ๑Richard Gray, ${ }^{1} \odot$ Boris V. Zemelman, ${ }^{1,2}$ and $\odot$ Daniel Johnston ${ }^{1,2}$ \\ ${ }^{1}$ Center for Learning and Memory and ${ }^{2}$ Department of Neuroscience, University of Texas, Austin, Texas 78712
}

Fragile X Syndrome (FX) is generally considered a developmental disorder, arising from a mutation that disrupts the transcription of Fragile X Mental Retardation Protein (FMRP). However, FMRP regulates the transcription of other proteins and participates in an unknown number of protein-protein interactions throughout life. In addition to known developmental issues, it is thus likely that some dysfunction is also due to the ongoing absence of FMRP. Dissociating dysfunction due to developmental dysregulation from dysfunction due to the continued absence of FMRP is necessary to understand the different roles of FMRP and to treat patients effectively throughout life. We show here that FX model mice display substantial deficits in a PFC-dependent task. We then use conditional knock-out mice to eliminate FMRP only in the PFC alone of adult mice. We observe an increase in the proportion of nonlearners and a delay in the onset of learning in both FX and conditional knock-out mice. The results suggest that these deficits (1) are due to the absence of FMRP in the PFC alone and (2) are not the result of developmental dysregulation. Furthermore, PFC-associated deficits are rescued by initiating production of FMRP in adult conditional restoration mice, suggesting that PFC dysfunction may persist as long as FMRP is absent and therefore can be rescued after development. The data suggest that it is possible to dissociate the roles of FMRP in neural function from developmental dysregulation, and that PFC function can be restored in the adult FX brain.

Key words: associative learning; autism spectrum disorder; Fragile X Syndrome; prefrontal cortex; trace eyeblink conditioning

Significance Statement

The absence of Fragile X Mental Retardation Protein (FMRP) from birth results in developmental disabilities and lifelong impairments. We show here that in mouse models PFC dysfunction in Fragile X Syndrome (FX) can be attributed to the continued absence of FMRP from the PFC, independent of FMRP status during development. Furthermore, initiation of FMRP production in the PFC of adult FX animals rescues PFC function. The results suggest that at least some FX-specific neurological defects can be rescued in the adult FX brain after development.

\section{Introduction}

In humans, Fragile X Syndrome (FX) is an autism spectrum disorder and the most common heritable cause of mental disability

Received March 1, 2017; revised May 9, 2017; accepted June 10, 2017.

Author contributions: J.J.S., R.A.C., and D.J. designed research; J.J.S. and W.T. performed research; J.J.S., R.A.C., R.G., and B.V.Z. contributed unpublished reagents/analytic tools; J.J.S., R.A.C., J.M.D., and C.P. analyzed data; J.J.S., R.A.C., and D.J. wrote the paper.

This work was supported by FRAXA and the McKnight Foundation. We thank David Nelson for contributing the conditional fmr 1 mouse lines used in this research; and Amanda Heatherly and Meagan Volquardson for excellent technical support.

The authors declare no competing financial interests.

*J.J.S. and R.A.C. contributed equally to this study.

Correspondence should be addressed to Dr. Jennifer J. Siegel, Center for Learning and Memory, University of Texas at Austin, 1 University Station Stop C7000, Austin, TX 78712-0805. E-mail: jenni@mail.clm.utexas.edu.

DOI:10.1523/JNEUROSCI.0571-17.2017

Copyright $\odot 2017$ the authors $\quad 0270-6474 / 17 / 377305-13 \$ 15.00 / 0$
(Coffee et al., 2009). The disorder results from the transcriptional silencing of the $f m r 1$ gene and a global loss of its protein product, Fragile X Mental Retardation Protein (FMRP) (Pieretti et al., 1991; Verheij et al., 1993) FMRP is an RNA binding protein that regulates the translation of hundreds of gene products. Many of the encoded proteins play key roles during development (Brown et al., 2001; Darnell et al., 2001, 2011), and their aberrant expression leads to developmental abnormalities (Darnell et al., 2001; Bernardet and Crusio, 2006; Bray et al., 2011; Martin and Huntsman, 2012; He et al., 2014). In addition to developmental effects, FMRP also regulates the translation of multiple ion channel subunit mRNAs (Brown et al., 2010; Osterweil et al., 2010; Brager and Johnston, 2014; Kalmbach et al., 2015), and binds directly to ion channels, modulating neuronal function throughout life (Ramos et al., 2006; Brown et al., 2010; Zhang et al., 2012; Brager 
and Johnston, 2014; Contractor et al., 2015; Wahlstrom-Helgren and Klyachko, 2015). Disentangling the multiple roles of FMRP during development and its ongoing function in adulthood remains an important challenge both in understanding the disease and for targeting interventions at different life stages.

A number of symptoms associated with FX (and the autistic phenotype in general) can be attributed at least in part to PFC dysfunction. Attention deficits, hyperactivity, perseverating behaviors, working memory deficits, and a lack of behavioral inhibition have all been associated with PFC function (Munir et al., 2000a, b; Wilding et al., 2002; Bray et al., 2011). In the FX model mouse, however, quantifying deficits in such higher-order adaptive behaviors has been challenging (Bernardet and Crusio, 2006; Krueger et al., 2011; Kramvis et al., 2013). Although hyperactivity and behavioral perseveration have been reported in FX mice, these deficits are modest or disappear after a day or two of additional observation (Bernardet and Crusio, 2006). Working memory tasks similar to those used in human patient studies have revealed modest or no differences in performance relative to wild-type (WT) mice (Mineur et al., 2002; Yan et al., 2004). Although there is substantial evidence of debilitating PFC dysfunction in FX patients, to date it has been difficult to investigate this dysfunction in the mouse model (Bernardet and Crusio, 2006), perhaps due to the lack of a sensitive and reliable behavioral readout of PFC function.

Recently, we developed trace eyeblink conditioning (TEC) procedures for use in mice and reported that both the acquisition and the ongoing performance of conditioned eyelid responses (CRs) are remarkably sensitive to the disruption of a restricted region of PFC (Siegel et al., 2015). Eyeblink conditioning is a simple associative task in which presentation of a cue (such as a light) predicts a puff of air to the eye. With training, animals learn to close the eyelid in anticipation of the puff whenever the cue is presented (see Fig. 1A). The task becomes PFC-dependent when a stimulus-free interval separates the cue and air-puff (Kalmbach et al., 2009; Siegel et al., 2015). Critically, we have identified a restricted region of the caudal PFC that is necessary for TEC in mice (Siegel et al., 2015). Here we use TEC to probe the nature of prefrontal dysfunction in the FX model mouse, and show that eliminating production of FMRP in the PFC alone in adult mice leads to a dramatic deficit in learning. Furthermore, initiating the production of FMRP in the adult PFC, after development, rescues performance in FX mice. The results suggest that deficits in adaptive behavior due to PFC dysfunction are at least partially due to the ongoing absence of FMRP and are not entirely developmentally linked. The findings suggest new possibilities for rescuing PFC dysfunction in FX patients after development.

\section{Materials and Methods}

Subjects. For the first experiment, FX mice and their WT littermates were obtained by crossing $f m r 1^{-1 y}$ mice in our facility (Brager et al., 2012; Kalmbach et al., 2015) with female C57BL/6 J mice (The Jackson Laboratory). The resulting heterozygous females $\left(\mathrm{fmrl}^{-/+}\right)$were then crossed with male C57BL/6J mice (The Jackson Laboratory), and male progeny $\left(f m r 1^{-l y}\right.$ and $\left.f m r 1^{+/ y}\right)$ used for behavioral experiments. The parents of the experimental progeny were functionally WT mice (heterozygous mothers have one functional fmrl gene, and so would exhibit a WT phenotype). For the second and third experiments, conditional fmrl KO (cKO) and conditional fmrlON (cON) breeding mice were acquired (D. Nelson, Baylor College of Medicine) and maintained in our facility. Depending on the mouse strain, Cre recombinase expressed regionally using adeno-associated virus (rAAV-Cre) either eliminates (in cKO mice) or initiates (in cON mice) production of FMRP in virus-infected neurons (Mientjes et al., 2006; Guo et al., 2011). For Experiment 3, cON male mice were also paired with female heterozygous $\mathrm{CON}$ mice to provide an additional WT littermate control for those experiments. The colony was maintained on a reverse light-dark schedule (lights off at 9:00 A.M. and lights on at 9:00 P.M.), and food and water were available ad libitum throughout all experiments. Behavioral experiments occurred during the animals' active dark phase, and red-light conditions were maintained throughout behavioral procedures. Mice were 10-16 weeks old at the time of surgical procedures. All procedures were approved by the University of Texas at Austin Institutional Animal Care and Use Committee in accordance with National Institutes of Health guidelines.

Experimental design and statistical analysis factors. For all experiments, littermates were used as control subjects, and groups of subjects trained either during overlapping timeframes (for FX and cON experiments), or as 2 large groups (cKO mice). This was due to the breeding schemes used (simultaneous breeder pairings or staggered). Each subgroup of simultaneously trained mice consisted of both experimental and control animals for a fully balanced design in all cases. Group and bootstrapped data over training days are shown as median \pm 25 th -75 th interquartile range (IQR) to relay the most accurate representation of data distributions at various time points. Additional post hoc tests on performance, wheel running, and unconditional responses were tested for normality using the Kolmogorov-Smirnov (K-S) method and compared using paired or independent-groups $t$ tests, as indicated (normality results given in Results). Statistical analyses were performed in Igor Pro (version 6.37, Wavemetrics). Power analyses were performed using $\mathrm{G}^{\star}$ Power (version 3.1.9.2).

Experiment 1: Experimental numbers for FX mice and their WT littermates were calculated based on power analyses of preliminary data from FX ( $n=25$ progeny of homozygous breeders) and C57BL/6J ( $n=$ $16 \mathrm{C} 57 \mathrm{BL} / 6 \mathrm{~J})$ mice, which showed an effect size of 1.60 . Power analysis indicated sample sizes of 26 mice/group as sufficient to detect differences based on a one-tailed $t$ test on the final day of training, yielding a power of 0.997. Groups of littermates were trained as described below until that number was approached ( $n=25$ and $n=24$ of WT and FX littermates, respectively). Because distributions of data for both groups were significantly skewed at various time points during learning (as typically observed in acquisition curves), a parameter-free test based on the same logic behind the $t$ test was used (see Behavioral training and analyses). As described below, Bonferroni corrections were invoked for all family-wise comparisons.

Experiments 2 and 3: Because of the complexity of experiments that included injections of rAAV-Cre in the PFC and the large effect size observed in Experiment 1, the numbers of mice per group were reduced by approximately half for these experiments $(n=13$ and $n=12$ for cKO experimental and controls; $n=12, n=14$, and $n=10$ for cON experimental, WT controls, and cON controls, respectively; see below for further details regarding control groups). The result was a corresponding reduction in statistical power (to 0.51 and 0.60 for $\mathrm{cKO}$ and $\mathrm{cON}$ experiments, respectively) and therefore a decrease in the probability of detecting smaller but significant group differences. This was reasonable because only a large effect would firmly support (or fail to support) our hypothesis in each experiment. Accordingly, post hoc power analyses indicated lower but still large effect sizes for both experiments during the last training sessions (1.21 and 1.29 for $\mathrm{cKO}$-injected/cKO-controls and $\mathrm{cON}$-injected/cON-controls, respectively). The same statistical methods used to compare group differences in Experiment 1 were applied to these experiments.

Surgical procedures. All mice were surgically implanted with a customfabricated titanium headplate for head fixation on a running wheel during training as described previously (Siegel et al., 2015). Anesthesia was induced with $3 \%$ isoflurane mixed with medical grade oxygen and maintained at surgical depth with $1 \%-2 \%$ isoflurane throughout procedures. Animals were placed in a stereotaxic apparatus and injected with $0.15 \mathrm{ml}$ of Rimadyl ( $1 \mathrm{mg} / \mathrm{ml}$, s.c.). Mice receiving craniotomies also received $0.03 \mathrm{ml}$ of dexamethasone $(2 \mathrm{mg} / \mathrm{ml}$, s.c.). The skull was prepared by scalping the crown, removing the fascia, then scoring the skull with the tip of a scalpel blade. After the skull was cleaned and dried, a layer of low-viscosity cyanoacrylate was applied over the surface of the exposed skull. An initial layer of Metabond (Parkell) was applied over the cyano- 
acrylate, the titanium headplate placed, and additional Metabond used to cement the headplate to the skull. Mice were given a minimum of 1 week to recover before beginning acclimation to the running wheel and behavioral training. $\mathrm{cKO}$, Con, and their WT littermates also received $2 \times 3$ $\mathrm{mm}$ craniotomies and stereotaxic unilateral injections of rAAV:mSyn: Cre (recombinase expressed from a mouse synapsin promoter, $2.5 \times$ $10^{11}$ genomes/ $\mu$ l) (Borghuis et al., 2011) in the TEC-specific region of the PFC (caudal anterior cingulate and medial agranular regions) (Siegel et al., 2015) (90 nl injected at anteroposterior coordinates 1.0, 1.25, and $1.5 \mathrm{~mm}$ from bregma, $0.5 \mathrm{~mm}$ lateral to the midline at $1.2 \mathrm{~mm}$ below brain surface; and $30 \mathrm{nl}$ at each of the same anteroposterior coordinates $0.8 \mathrm{~mm}$ lateral and $0.8 \mathrm{~mm}$ below the brain surface; 6 total injection sites separated by $250 \mu \mathrm{m})$. Unilateral injections were used based both on anatomical projection patterns and functional inactivation: (1) anatomical tracing indicates unilateral projections from PFC to the pons, and from the pons to the cerebellum (Siegel et al., 2015); and (2) unilateral inactivation of either the PFC or the cerebellum abolishes CRs in trained mice (Siegel et al., 2015). cON WT littermates received the same injections of rAAV-Cre, and cKO control mice received injections of rAAVtdTomato at the coordinates given above. $\mathrm{CON}$ sham controls received the same craniotomies, but no rAAV was injected. Mice injected with rAAV and their controls were given 6 weeks for surgical recovery and protein turnover/production before acclimation and behavioral training. This time point was chosen based on preliminary tests using a 4 week recovery period, which suggested that behavioral effects may not be stable across animals at that time. To ensure that FMRP is fully degraded and for the downstream effects of FMRP loss and protein turnover in neurons be stable in all animals at the start of behavioral training, the postinjection window was extended to 6 weeks. It should be noted that the Cre-mediated excision of floxed sites is a single and permanent event, and so there appeared to be no detriment to extending the time window as a precautionary measure.

Behavioral training and analysis. The acclimation, TEC training procedures, and eyelid behavior analyses used have been previously described (Siegel et al., 2015). The experimenter was blind to the genotype/ experimental manipulation of mice during training, which was not revealed until after quantification of eyelid behavior. Mice were first acclimated to head-fixation on top of a freely rotating cylinder for $3 \mathrm{~d}$ (for 15,30 , and $30 \mathrm{~min}$ ) before TEC training began. Mice received 1 session/d of $60 \mathrm{TEC}$ trials/session for $14 \mathrm{~d}$. Training trials were given at an interval of $15 \pm 5 \mathrm{~s}$ and began with presentation of a $50 \mathrm{~ms}$ blue light LED as the conditional stimulus (CS), followed by a $250 \mathrm{~ms}$ stimulus-free trace interval and terminated with a $20 \mathrm{~ms}$ air-puff to the eye (as the unconditional stimulus [US]; see Fig. $1 A$, top) while head-fixed and permitted to run freely on the rotating cylinder. The first and then every fifth trial was a CS-only probe trial. Eyelid behavior was monitored with a high-speed camera (200 or $250 \mathrm{fps}$ ). Eyelid responses for each trial were analyzed off-line using custom software running in Igor Pro (Wavemetrics). For each session, a region of interest (ROI) was selected over the center of the eye and applied to each frame of a session. Pixels within that ROI were thresholded such that the eye was designated as black and the surrounding fur as white (see Fig. 1A, bottom). The fraction-of-eyelid closure (FEC) was calculated as the ratio of white:black pixels within the ROI for each frame of a trial (e.g., see Fig. $1 A$, bottom right), for all trials within a session. Trials with eyelid movements exceeding a SD of 0.015 for the 200 $\mathrm{ms}$ before CS onset were considered invalid and excluded ( $<5 \%$ of trials). A CR was scored for valid trials in which the FEC exceeded 0.10 between CS and US onset (e.g., see Fig. $1 \mathrm{~A}$, bottom right). Performance (CR rate) was calculated as the proportion of valid trials with a $\mathrm{CR} /$ number of valid trials (expressed as a percentage). CR amplitude and latency to peak (timing) were calculated from the valid CS-only probe trials for each session. CR amplitude was defined as the maximum FEC observed after CS onset, with latency to peak taken as the time between CS onset and the maximum FEC observed. The reflexive blink response to the air-puff was also measured and taken as the maximum amplitude after US onset. Group differences in air-puff responses were tested by taking the median amplitude observed across trials for each training session for each mouse and averaging over days for a given mouse. Wheel running behavior was recorded as previously described (Siegel et al.,
2015). In short, the side of the rotating cylinder was fixed with a concentric black-and-white repeating quadrature pattern, and movement measured by temporal changes in the infrared light reflected from a point on the wheel's edge as detected with a paired LED and phototransistor (SEN-11769, Sparkfun). Movement was sampled at $20 \mathrm{~Hz}$ and written to file by an Arduino microcontroller. Momentary speed was calculated by the number of light changes during the sampling epoch and converted to centimeters per second. Group differences were tested by calculating the percent time running during each training session for each mouse and averaging over days for a given mouse.

Group differences in learning were evaluated for each training day using a parameter-free test similar to a $t$ test but independent of normality and homogeneity of variance assumptions. Samples were bootstrapped to derive the most likely sampling distribution of the population that those samples came from (Kulesa et al., 2015), and the K-S two-sample test then used to determine whether the parent sampling distributions were significantly different (with Bonferroni corrections implemented for the number of repeated measures in all cases). For each time point, the sampling distribution of the median was derived separately for FX and WT mice by resampling (with replacement) the same number of observations for each group and recording the median measure of central tendency, for 10,000 iterations (bootstrap). The K-S test was then used to test whether the derived sampling distributions of FX and WT mice at each time point were significantly different. The K-S test will be sensitive to differences in the shape of distributions (normal vs highly skewed) as well as differences in central tendency. Significance was determined by comparing the obtained $d$ to $d_{\text {crit }}$, where $d_{\text {crit }}$ was calculated using the numbers of observations in the original sample groups as follows:

$$
d_{\text {crit }}=\alpha_{\text {coef }}\left(\sqrt{\left(\left(\mathrm{n}_{\mathrm{FX}}+\mathrm{n}_{\mathrm{WT}}\right) /\left(\mathrm{n}_{\mathrm{FX}} \mathrm{n}_{\mathrm{WT}}\right)\right)}\right) .
$$

The $\alpha_{\text {coef }}$ was determined by the double exponential (fit to known estimations of $\alpha$ coefficients for the K-S test) as follows:

$$
\begin{aligned}
& 1.1352+\left(0.56308 * \exp \left(-18.8 * \alpha_{\text {Bonf }}\right)\right) \\
&\left(+0.34548^{*} \exp \left(-278.41 * \alpha_{\text {Bonf }}\right)\right),
\end{aligned}
$$

where $\alpha_{\mathrm{Bonf}}$ is the family-wise error $(\alpha=0.05)$ divided by the total number of comparisons being made (Bonferroni correction).

FMRP immunohistochemistry. After behavioral training was complete, mice were given intraperitoneal injections of $0.15 \mathrm{ml}$ ketamine mixed with xylazine $(10 \mathrm{mg} / \mathrm{ml}$ xylazine in $90 \mathrm{mg} / \mathrm{ml}$ ketamine $)$ and perfused intracardially with modified ACSF $\left(2.5 \mathrm{~mm} \mathrm{KCl}, 1.25 \mathrm{~mm} \mathrm{NaH}_{2} \mathrm{PO}_{4}, 25 \mathrm{~mm}\right.$ $\mathrm{NaHCO}_{3}, 0.5 \mathrm{~mm} \mathrm{CaCl}_{2}, 7 \mathrm{~mm} \mathrm{MgCl}, 7 \mathrm{~mm}$ dextrose, $205.5 \mathrm{~mm}$ sucrose, $1.3 \mathrm{~mm}$ ascorbic acid, and $3.7 \mathrm{~mm}$ pyruvate) followed by $4 \%$ PFA in $0.02 \mathrm{M}$ phosphate buffer. Brains were cryoprotected in a $30 \%$ sucrose $/ 4 \%$ PFA solution overnight or until equilibrated. Tissue was sectioned at $50 \mu \mathrm{m}$ using a sliding microtome (Leica Microsystems) on a temperature controlled freezing stage (Physitemp). Coronal sections of PFC (from bregma 1.75 to 0.75 , previously shown to support TEC) (Siegel et al., 2015) were taken and stored in PBS for $24-48 \mathrm{~h}$. For immunofluorescent staining, sections were rinsed $3 \times 5 \mathrm{~min}$ in PBS and then transferred to a hot sodium citrate bath for antigen retrieval $\left(85^{\circ} \mathrm{C}-95^{\circ} \mathrm{C}, \mathrm{pH} 6.0,30 \mathrm{~min}\right.$ incubation). Sections were rinsed and placed in blocking solution $(10 \%$ normal goat serum and $0.5 \%$ Triton X-100 [NGST]) at room temperature for $3 \mathrm{~h}$, then rinsed and placed in primary antibody (1:1 of mouse supernatant anti-FMRP in NGST, Developmental Studies Hybridoma) for $48 \mathrm{~h}$ at $4^{\circ} \mathrm{C}$. After rinsing, slices were placed in secondary antibody (1:500 Alexa-488 goat antimouse IgG in NGST, Thermo Fisher Scientific) for $3 \mathrm{~h}$ at room temperature, rinsed several times, and mounted on Microfrost Plus slides (Fisher Scientific). Mounted sections were coverslipped with Fluormount-g (Southern Biotechnology) and light-protected.

Imaging and volumetric reconstruction of FMRP-negative and-positive tissue. The experimenter was blind to behavioral performance during imaging and quantification of FMRP-negative or -positive tissue. Images of FMRP immunohistochemistry staining in the PFC were acquired using a Zeiss Axio Imager Z2 microscope running AxioVision software (version 4.8.2, Carl Zeiss). Multichannel images included independent reflected wavelength bands for blue (for autofluorescence to identify gross anatomical structure) and green (for FMRP immunohistochemical 
staining). Standard Zeiss filter sets (Carl Zeiss) were used to separate excitation/emission wavelengths (set 49 for blue: excitation 365, dichroic 395, emission 445/50; set 38 for green: excitation 470/40, dichroic 495, emission 525/50). Images were acquired as multichannel mosaics in 12 bit or 16 bit grayscale format. Following alignment of tiled images and assembly into a single continuous image using the AxioVision software, individual channels were exported as unmodified 8 bit or 12 bit TIF files. Image processing and quantification were performed in FIJI (Schindelin et al., 2012). Images were processed to increase signal/noise using a rolling ball background subtraction algorithm and adjustment of brightness/ contrast. The area of FMRP-negative (for cKO+PFC-Cre mice) or -positive tissue (for cON+PFC-Cre mice) was calculated for sections falling within the TEC-specific region of PFC (Br 1.75-0.75) (Siegel et al., 2015). Volume of FMRP-negative or -positive tissue for each section was calculated by estimating the intersection interval and multiplying by the area of FMRP-negative/positive tissue observed. The total volume of FMRP-negative/positive tissue for each mouse was determined by summing the volumes of all sections falling within the TEC-specific range. Reconstruction of FMRP-negative or -positive tissue for each mouse was performed as previously described (Siegel et al., 2015). For each representative section from each mouse, the opacity of the area of FMRPnegative or -positive tissue was set to $10 \%$, and the areas from all animals overlaid. The grayscale image compiled across animals for each brain section was converted to a color scale to represent the number of animals with overlapping regions of FMRP-negative or -positive tissue.

\section{Results}

FX mice show significant impairments in TEC

The acquisition of TEC in mice has been shown to be highly sensitive to PFC disruption (Siegel et al., 2015). To investigate whether the PFC of the FX model mouse is functionally compromised by the absence of FMRP, FX mice and their WT littermates were trained for $14 \mathrm{~d}$ in TEC. FX mice showed remarkable deficits in TEC acquisition, including a higher proportion of nonlearners (defined as $<10 \%$ CRs for all training days), a delayed onset for learners ( $>50 \% \mathrm{CRs}$ ), and differences in CR expression (lower asymptotic rates, lower response amplitudes, and poorer timed responses).

Figure $1 B$ (top) shows the median and 25th-75th IQRs for all FX and WT animals. Bootstrapping was used to derive the most likely sampling distributions (to infer the underlying population distributions) (Kulesa et al., 2015) for each group of animals on each day of training. The analysis indicates that FX and WT populations diverge in learning on the sixth day of training, with FX mice showing significantly lower performance for the rest of training $(n=25, n=24$, K-S test: $d>0.53, p<0.0035$ for each time point; Fig. $1 B$, bottom). The sampling distributions of FX mice do not depart significantly from zero until day 11 , whereas WT mice are significantly different from zero beginning on day 8 (one-tailed CI, $p<0.05$; Fig. $1 B$, bottom, arrows). The data demonstrate that FX mice show less learning as a group with a delayed onset relative to WT littermates. The decreased learning is due in part to the higher proportion of animals in the FX group that showed little, if any, evidence of learning (nonlearners, $<10 \% \mathrm{CR}$ rates, $38 \%$ of FX vs only $8 \%$ of WT mice; Fisher Exact test $=6.12$, $p=0.01$; Fig. 1C; behavioral examples shown in Fig. 1D).

Previous work has shown that FX mice have deficits in sensory processing (including visual cortex) and cerebellar-dependent motor function (Koekkoek et al., 2005; Dölen et al., 2007; Michalon et al., 2012), which may have affected the ability of these mice to learn the task. FX mice responded to the air-puff with reflexive blinks that were not different from WT, suggesting that insensitivity to the US cannot explain the difference in learning (mean \pm SEM for FX: $0.87 \pm 0.02$ FEC, WT: $0.89 \pm 0.01 \mathrm{FEC}, \mathrm{df}=23, \mathrm{df}=$ $24, t=-1.18, p=0.25$; normality for WT: $d=0.14$ and $p=0.35$,
FX group data violated normality, $d=0.27$ and $p=0.02$; however, a Wilcoxon Rank Test yielded the same result, $U=354.5$, $p=0.14)$. To test directly whether sensory or motor deficits alone may have precluded the learning or expression of TEC in FX mice, nonlearners were trained using the same stimuli under the same conditions in a PFC-independent delay conditioning training protocol (in which the $170 \mathrm{~ms}$ light CS and air-puff overlap and coterminate) (Siegel et al., 2015). Most FX TEC nonlearners were able to learn to express CRs in the delay task (6 of 9 mice, 31\%-85\% maximum CR rates; Fig. $1 E$ ), similar to that observed for PFC-lesioned WT mice in a previous study (in both studies, a proportion of control TEC nonlearners also fail to learn) (Siegel et al., 2015). A paired comparison between CR rates observed on the final day of TEC versus that observed for delay showed significant increases in performance after delay, further indicating that the inability to acquire TEC was likely not due to sensory processing or motor expression issues in these mice (mean \pm SEM, TEC day 14: $3.61 \pm 1.14 \%$ CRs, delay day 10: $33.85 \pm$ $10.11 \% ; t=3.16, \mathrm{df}=8, p=0.007$; normality test for TEC: $d=$ 0.25 and $p=0.28$, delay: $d=0.19$ and $p=0.47)$. Finally, analysis of wheel running behavior during TEC showed that FX mice were neither "frozen" (mean \pm SEM, FX percent time running: $16.21 \pm 1.59, \mathrm{H}_{\mathrm{o}}=0 \%, \mathrm{df}=23, t=10.23, p<0.0001$; normality: $d=0.14, p=0.38$ ) nor hyperactive on the wheel during training, actually running slightly less than their WT counterparts (WT percent time running: $27.04 \pm 3.05$, paired $t$ test vs $\mathrm{FX}$ : $\mathrm{df}=24$, $\mathrm{df}=23, t=3.15, p<0.003$; normality for WT: $d=0.17$, $p=0.22$ ).

Although fewer FX mice learned TEC relative to WT, some FX mice did meet a $50 \%$ CR criterion on at least one of the $14 \mathrm{~d}$ of training. The performance rates of FX learners and WT learners were aligned to the criterion day to test whether these mice acquired CRs at the same rate (even with the delayed onset) and performed at the same level after criterion (Fig. 2A, left). Analysis revealed that FX and WT mice acquired the task similarly before and during learning, but FX mice performed at a lower asymptotic rate after criterion $(n=19, n=12, \mathrm{~K}-\mathrm{S}$ test: $d>0.65, p<$ 0.0045 for each time point; Fig. $2 A$, left). In addition to lower performance rates, FX mice also showed smaller amplitude CRs when normalized to learning onset (K-S test: $d>0.63, p<0.005$; Fig. $2 A$, middle) and modestly earlier timing, possibly as an adaptive strategy to express CRs and protect the eye from the air-puff (K-S test: $d>0.63, p<0.005$; Fig. $2 A$, right; behavioral examples shown in Fig. 2B).

FX patients have been described as showing perseverating behaviors (Wilding et al., 2002). Therefore, we took advantage of the fact that some FX mice could express learning (albeit with deficits) to test whether they perseverated in expressing CRs during extinction training, when only the light cue and no air-puff was presented. Although FX mice showed performance deficits before and after extinction training (K-S test: $d>0.64, p<$ 0.005 ), during extinction of the task they learned to stop responding to the CS just as efficiently as their WT counterparts (K-S test: $d<0.64, p>0.005$; Fig. 2C)

\section{PFC-specific knock-out of FMRP in adult mice produces learning deficits}

A number of brain regions have been shown to support TEC in mice, including the cerebellum, which mediates expression of the learned motor response (Kalmbach et al., 2009, 2010; Siegel et al., 2015). To determine which, if any, of the observed TEC deficits in FX mice can be attributed to an absence of FMRP in the PFC alone, we used injections of rAAV-Cre targeted to the TEC- 
A

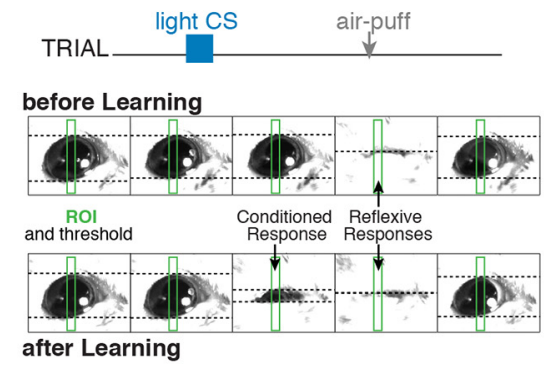

B Trace Conditioned Response Rates
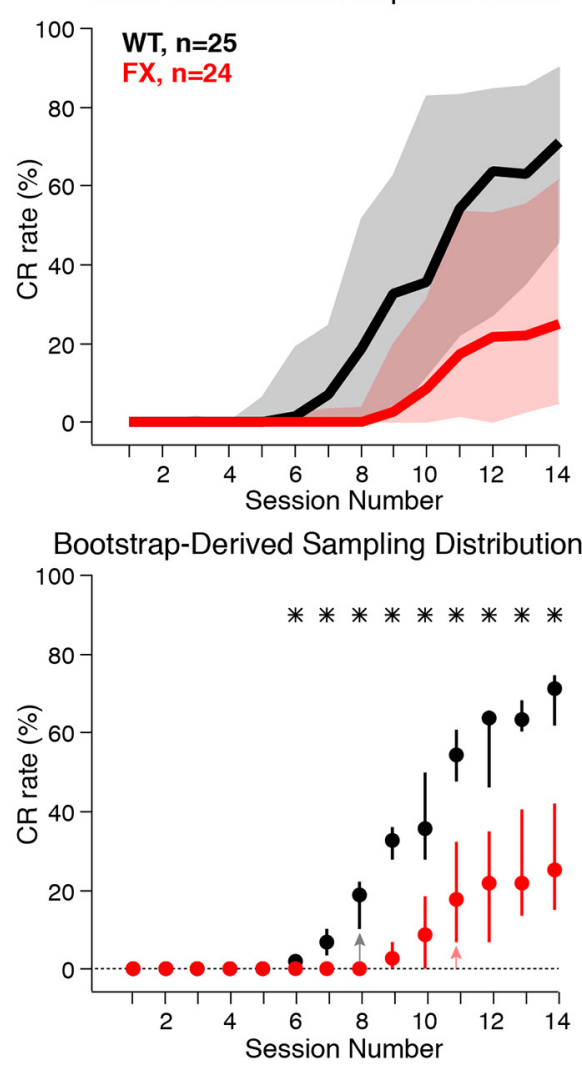

C

Proportions of Learners and Non-Learners
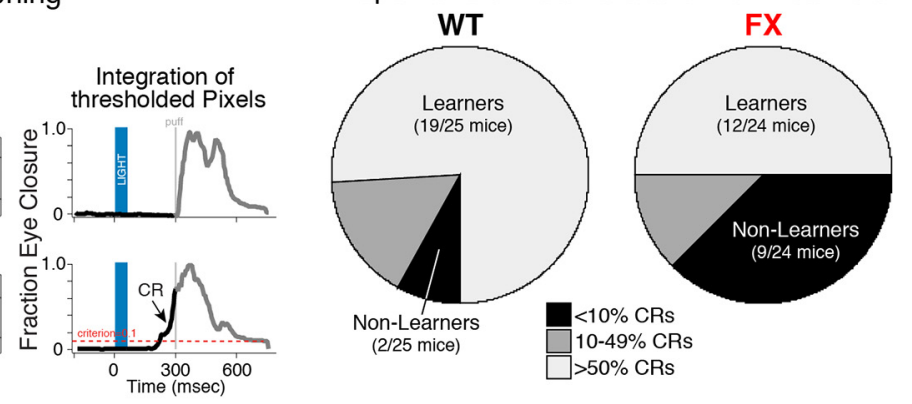

D

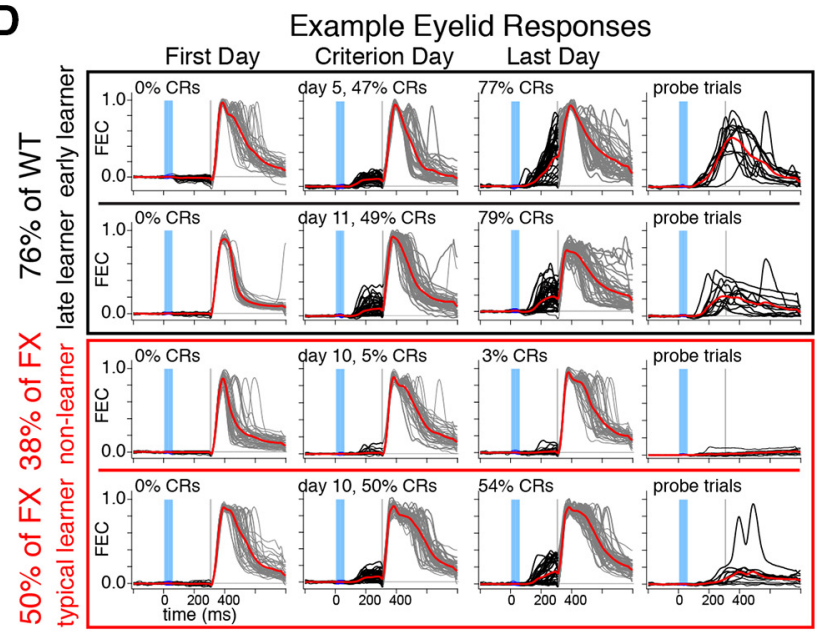

E PFC-Independent (Delay) Conditioning

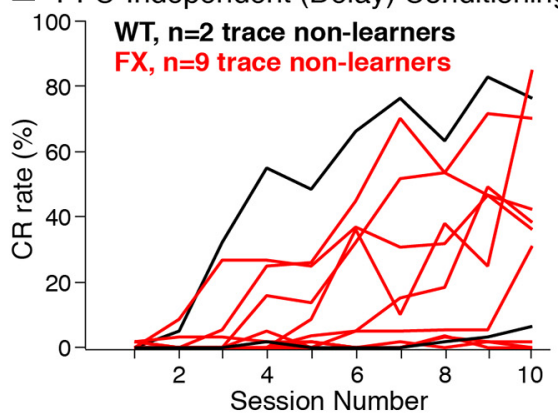

Figure 1. FX mice are impaired in the PFC-dependent trace eyeblink conditioning task. A, Mice are presented with a visual cue (blue LED) followed by a $250 \mathrm{~ms}$ stimulus-free interval terminating with an air-puff to the eye (top). Eyelid responses are measured with an infrared high-speed camera to determine FEC (bottom left). Before learning, mice close the eye only in response to the air-puff (top right), but with continued training learn to close the eye in anticipation of the air-puff ( $C R$; upward deflection indicates closure, bottom right). $\boldsymbol{B}$, Trace conditioned response rates over $14 \mathrm{~d}$ of training for FX and WT littermates (median \pm IQR, top), and the derived sampling distributions of the median based on bootstrapping (medians \pm IQRs, bottom). * Significant differences between sampling distributions on a given day of training (KS tests with Bonferroni correction, $p<0.0035$; see Materials and Methods). Arrows indicate the onset of learning (i.e., the first day that distributions were significantly different from " 0 " at 95 th percentile (I). FXand WT mice deviated in learning beginning on day 6 and differed in learning onset by $3 \mathrm{~d}$. C, FX mice showed significantly more nonlearners than WT (Fisher exact test, $p=0.01$ ). D, Example eyelid responses for 2 WT (top, early and late learner) and 2 FX mice (bottom, nonlearner and typical learner matched to late learning in WT), for the first day of training, criterion day (50\% (Rs), and last day of training. Each example shows all 48 paired training trials overlaid. Red represents average eyelid response. Blue bars represent light. Gray bars represent air-puff presentation. Even when matched for criterion day (late WT learning vs typical FX learner), the FX mouse showed fewer (Rs by the end of training with smaller amplitudes. Differences in CRs between WT and FX mice are clearly noted for light-only probe trials in which the air-puff was omitted (far right). E, FX and WT nonlearners were trained using the same stimuli in a non-PFC-dependent version of the task (i.e., delay conditioning) in which the light and air-puff coterminate. Most FX mice were able to express CRs when the PFC was not necessary for learning, indicating that previous learning deficits were not due to sensory or motor processing deficits.

specific region of PFC (caudal anterior cingulate and medial agranular regions) (Siegel et al., 2015) in adult $f m r 1-/ y$ cKO mice to block FMRP production from that point on ( $\mathrm{cKO}+\mathrm{PFC}-\mathrm{Cre}$, Fig. 3A) (Mientjes et al., 2006). Immunohistochemistry against FMRP confirmed that the recombinase treatment eliminated FMRP in the TEC-specific region of PFC (Fig. 3A). Cre-injected cKO mice showed significant deficits in TEC relative to their littermate cKO sham-injected controls (Fig. 3B). Further analysis revealed that $\mathrm{CKO}+\mathrm{PFC}-\mathrm{Cre}$ and $\mathrm{cKO}$ control populations di- verge and show reliably different $C R$ rates beginning on day 7 (similar to that observed between FX and WT mice; $n=13, n=$ 12 , K-S test: $d>0.72, p<0.0036$ for each time point; Fig. $3 B$, bottom). Also, similar to FX mice, PFC-specific knock-out of FMRP resulted in a delayed onset of learning (day 13 for cKO+PFC-Cre vs day 7 for cKO controls; one-tailed CI, $p<$ 0.05 ; Fig. $3 B$, bottom, arrows). Finally, a significantly higher proportion of $\mathrm{CKO}+\mathrm{PFC}-\mathrm{Cre}$ mice were nonlearners compared with cKO controls $(38.5 \%$ of cKO+PFC-Cre vs $0 \%$ of cKO control 
A
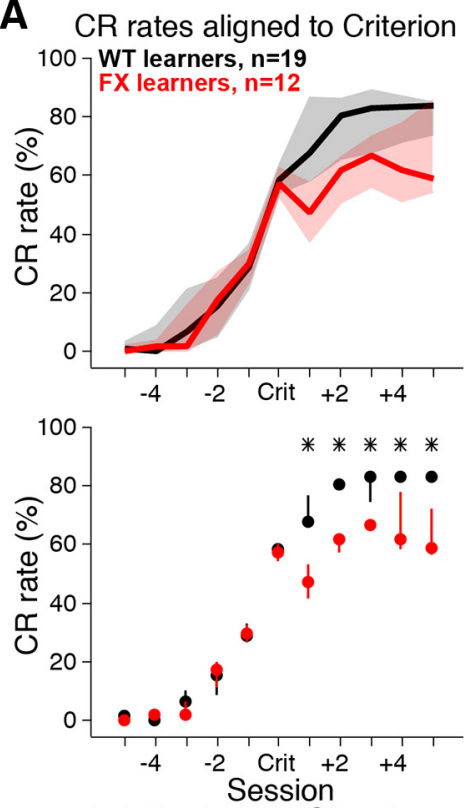

(relative to $50 \% \mathrm{CR}$ criterion)
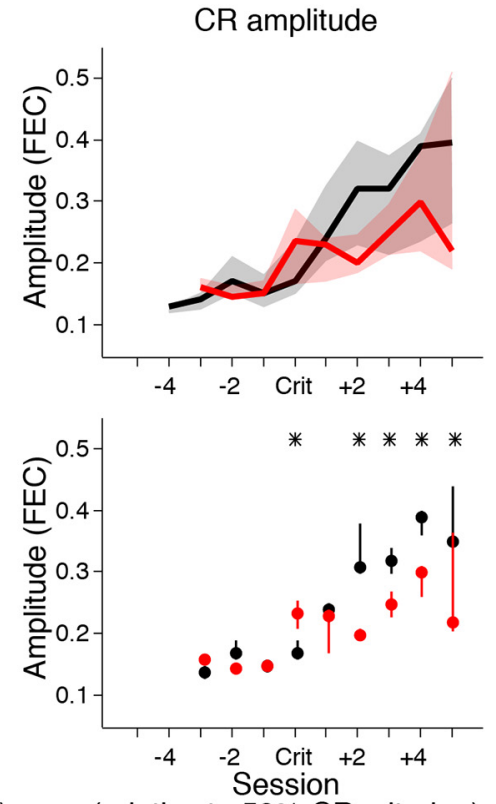

(relative to $50 \% \mathrm{CR}$ criterion)

B

Exemplar sessions 2 days post learning showing decreased CR rates, amplitude, and earlier timing in FX mice

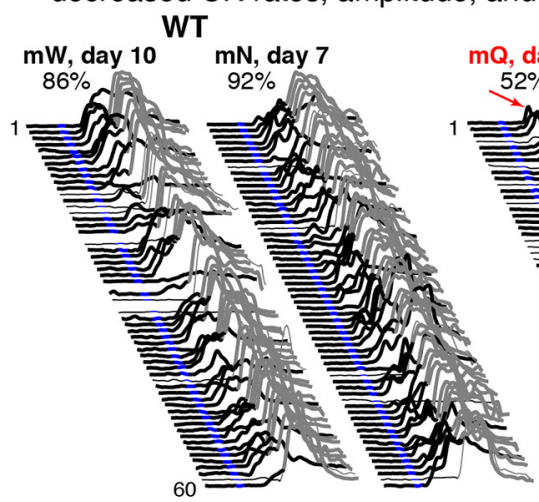
FX $\mathrm{mC}$, day 12

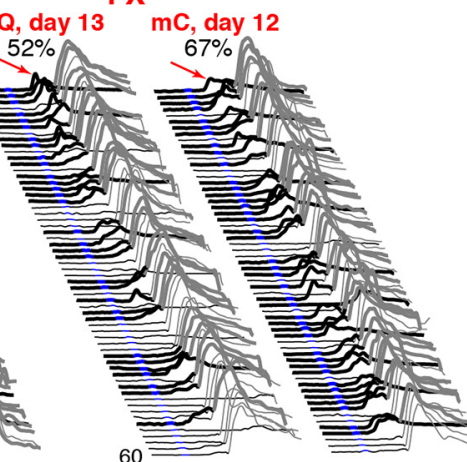

CR timing (latency to peak)

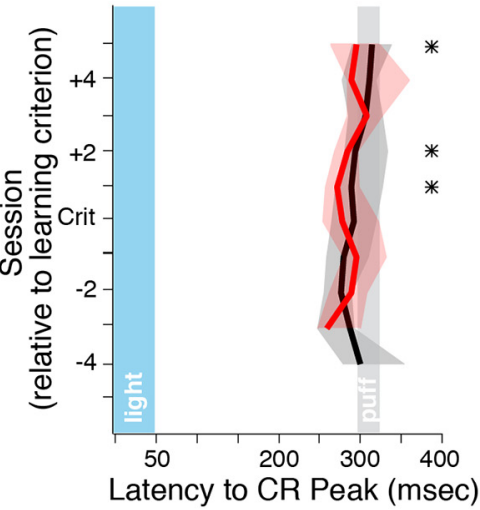

C Extinction and Reacquisition

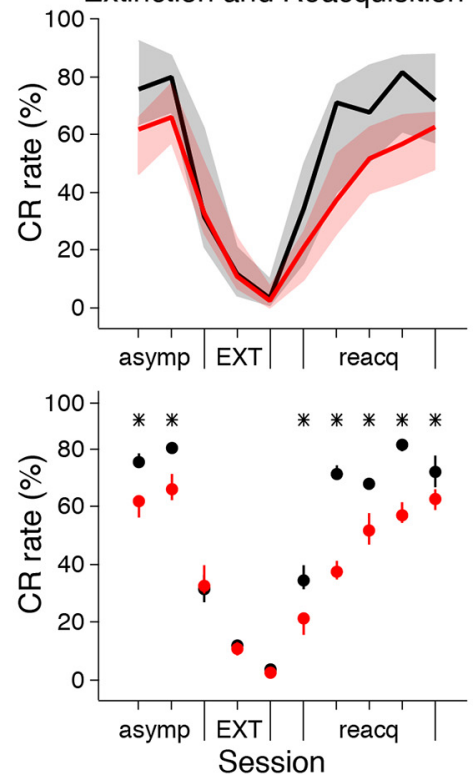

Figure 2. FX learners show deficits in CR expression, including lower asymptotic performance, response amplitude, and timing. $A$, CR rates (left), CR maximum amplitude (middle), and CR timing (latency to peak amplitude, right) in WT and FX learners, aligned by criterion session ( $>50 \%$ CRs; median \pm IQR). Bottom graphs, Bootstrapped sampling distributions of the medians (medians \pm IQRs). ${ }^{*}$ Significant differences between WT and FX distributions (KS tests with Bonferroni correction, (R rates: $p<0.0045$; amplitude and timing: $\left.p<0.005\right)$. $\boldsymbol{B}$, Example behavioral sessions 2 d after meeting criterion from two representative WT and FX mice. $m$, Individual mouse ID. Each line indicates eyelid behavior for a single trial (first trial at top, upward deflection indicates closure, time on $x$-axis). Blue represents light CS. Gray represents onset of air-puff and post-trial epoch. Higher performance, larger-amplitude CRs, and CR peaks are timed to air-puff delivery for WT mice relative to FX mice. Red arrows indicate early timing of CR peaks observed for many FX mice. C, CR rates (top) and bootstrapped sampling distributions of the median (medians $\pm I Q R s,{ }^{*} p<0.005$ ) for extinction (EXT) and reacquisition (reacq) training. FX mice were able to extinguish learned responses as efficiently as their WT littermates.

mice; Fisher Exact test $=5.77, p=0.02$; Fig. $3 C$ ). The data indicate that deficits in group performance over training days, the increased proportion of mice with a nonlearning phenotype, and the delayed learning onset can be attributed directly to the absence of FMRP from the PFC alone. Further, these deficits were observed after knocking out FMRP in the adult mouse, and therefore are likely due to the ongoing function of FMRP in the PFC after development.

Interestingly, $\mathrm{cKO}+\mathrm{PFC}-\mathrm{Cre}$ learners expressed $\mathrm{CRs}$ that were not significantly different from those of $\mathrm{cKO}$ control mice, which had FMRP intact throughout the brain (Fig. 4). Alignment of the learning curves of individual mice to criterion revealed no differences in asymptotic performance rates $(n=6, n=8$, K-S test: $d<0.94, p>0.005$ for each time point; Fig. $4 A$, left), in contrast to that observed for FX mice with a global absence of FMRP. Likewise, decreases in CR amplitude and earlier timing were not observed, although increases in amplitude and later timing were observed at some time points (fewer mice were sampled at these later time points due to the delayed onset of learning; amplitude: $d>0.93, p<0.006$ for each time point; timing: $d>$ $0.93, p<0.006$; Fig. $4 A$, middle and right; behavioral examples shown in Fig. $4 B$ ). The data suggest that the latter aspects of $C R$ expression (rate, amplitude, and timing) were not due to the absence of FMRP in the PFC, and therefore likely due to dysfunction in other brain regions that lack FMRP in the FX mouse, such as the cerebellum (Koekkoek et al., 2005).

Initiation of FMRP production in the PFC of adult FX mice results in the rescue of $P F C$-specific deficits

Although knock-out of FMRP in the PFC alone was sufficient to observe TEC deficits in adult mice, it is still possible that the absence of FMRP during development could preclude rescuing those deficits when FMRP expression is restored in the adult PFC. To address this question, we initiated the production of FMRP in 
A PFC-specific knockout of FMRP

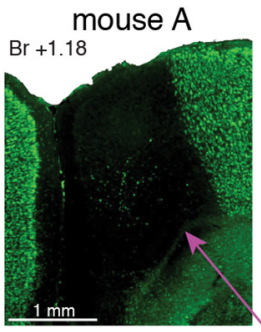
mouse B
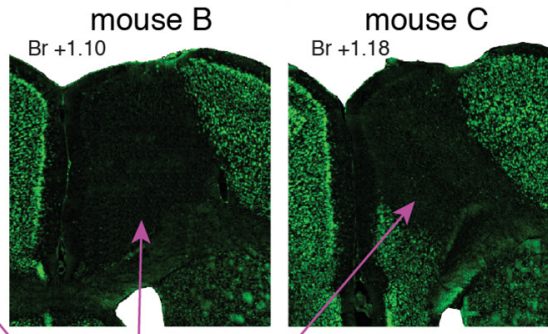

Volume of FMRP-negative tissue

FMRP-negative neurons

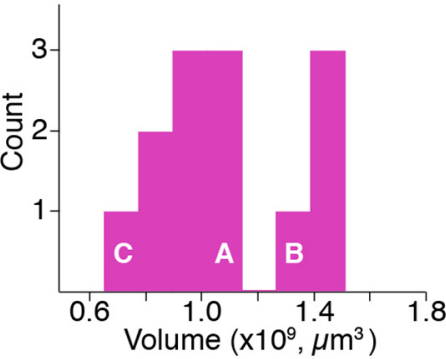

FMRP-negative tissue, $\mathrm{n}=13 \mathrm{cKO}+\mathrm{PFC}$-Cre mice

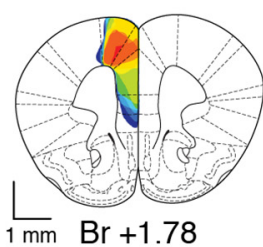

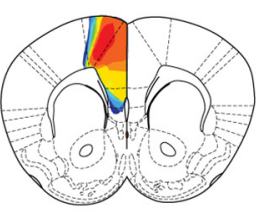

$\mathrm{Br}+1.42$

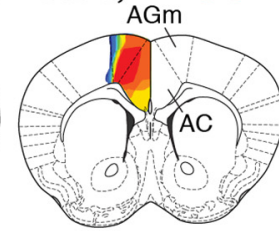

$\mathrm{Br}+1.18$

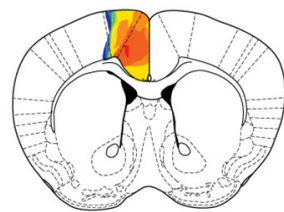

$\mathrm{Br}+0.98$

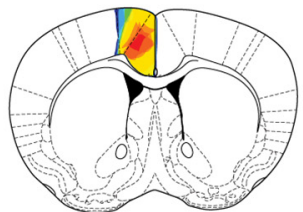

$\mathrm{Br}+0.74$

common areas

\section{B Trace Conditioned Response Rates}
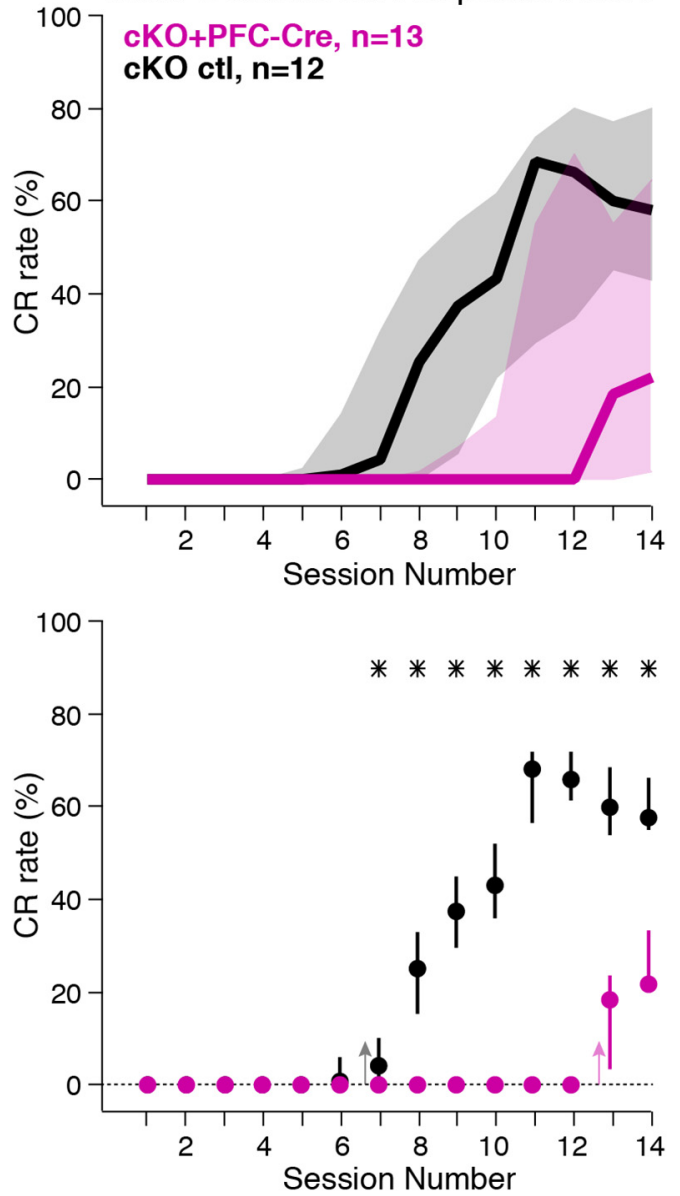

C Proportions of Learners and Non-Learners

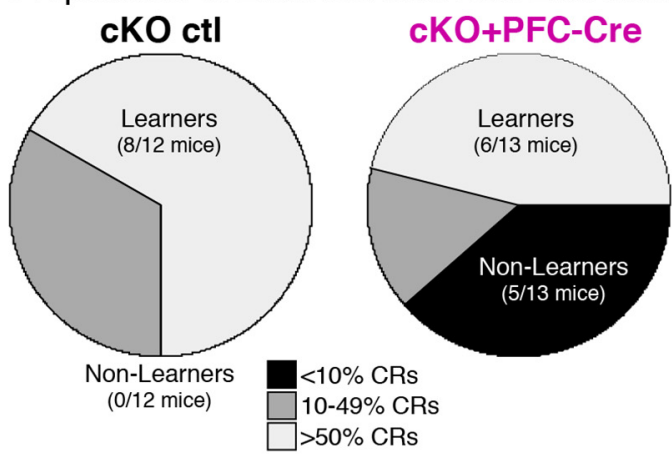

Figure 3. PFC-specific knock-out of FMRP in adult mice results in increased proportion of nonlearning mice and delayed learning onset. $\boldsymbol{A}$, FMRP immunohistochemistry from the PFC of 3 representative $\mathrm{CKO}+\mathrm{PFC}$-Cre mice (left), with total volumes ofFMRP-negative tissue for all mice shown on right (histogram). Letters indicate volumetric results from representative examples. Areas of FMRP-negative tissue were reconstructed for all cKO + PFC-Cre mice and showed considerable overlap in the medial agranular ( $\mathrm{GGm}$ ) and anterior cingulate (AC) regions of PFC previously shown to be critical for TEC. Bottom, Color scale: red represents regions where FMRP-negative tissue was observed for all 13 mice; cool colors represent regions where few mice overlapped. $B$, $C R$ rates over $14 \mathrm{~d}$ of training for CKO+PFC-Cre (magenta) and control mice (black, top), and bootstrapped sampling distributions of the median (bottom, medians \pm IQRs). Sampling distributions diverge significantly beginning on day $7\left({ }^{*} p<0.0036\right)$, and $\mathrm{CKO}+\mathrm{PFC}-$ Cre mice do not perform above " 0 " until day 13 (magenta arrow, 95 th percentile $\mathrm{Cl}$ ), indicating a delayed onset of learning for the group relative to control mice (black arrow, day 7). C, Similar to FX mice, $\mathrm{CKO}+\mathrm{PFC}$-Cre mice show a higher proportion of nonlearners relative to control mice (Fisher exact test, $p=0.02$ ). 
A
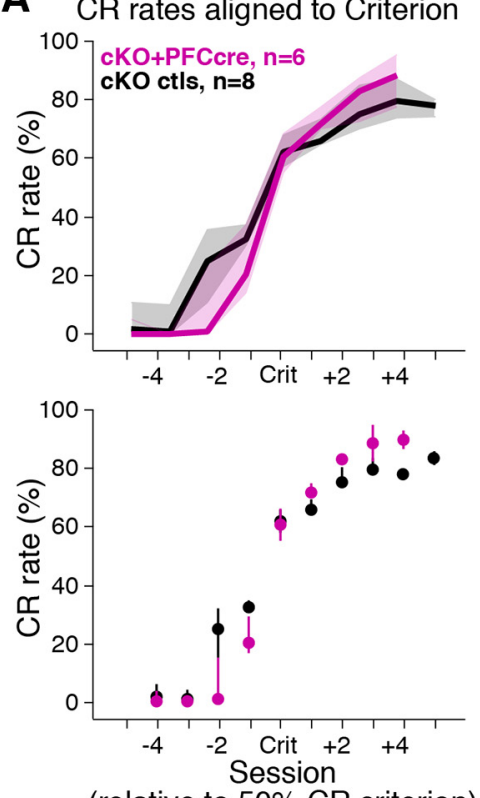

(relative to $50 \%$ CR criterion)
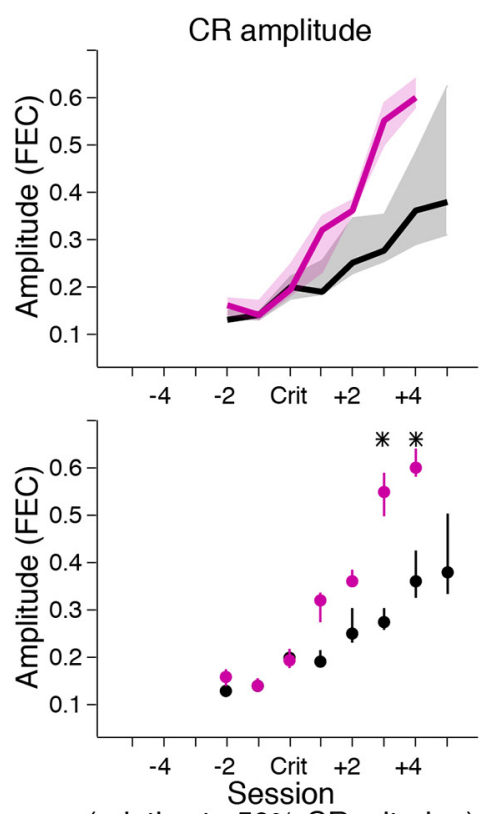

(relative to $50 \%$ CR criterion)

\section{CR timing (latency to peak)}

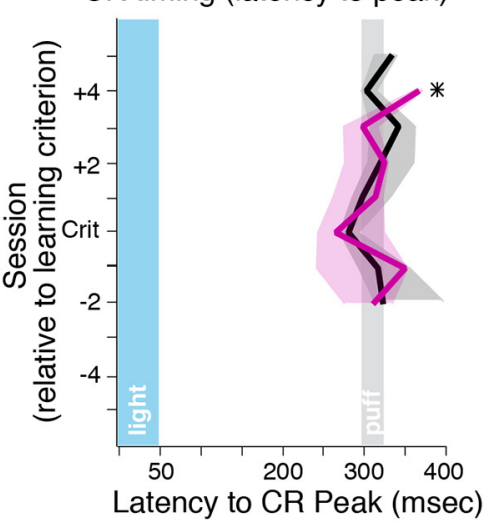

B

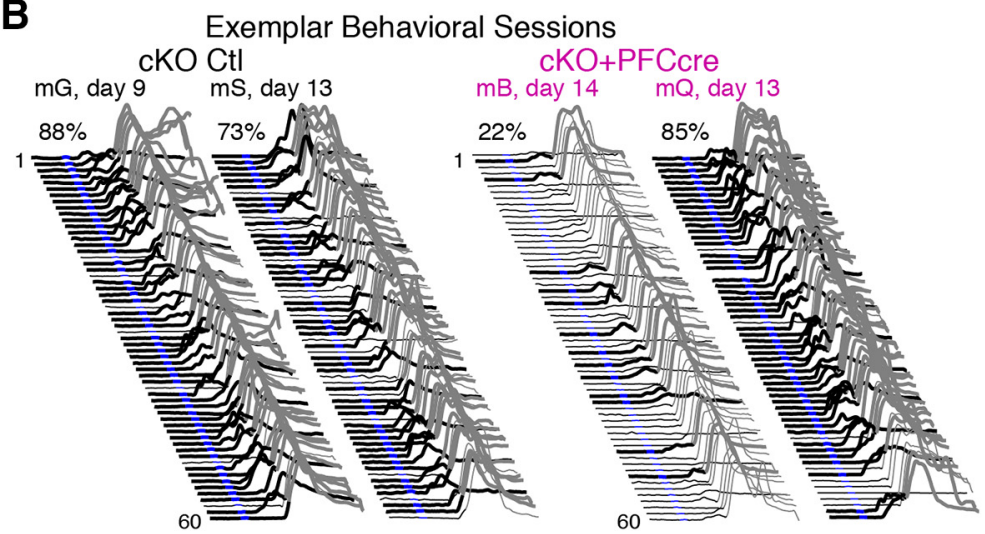

Figure 4. CKO + PFC-Cre mice that are able to learn do not show deficits in performance rate, $C R$ amplitude, or CR timing. $A$, CR rates (left), CR maximum amplitude (middle), and CR timing (latency to peak amplitude, right) in cK0+PFC-Cre (magenta) and cKO control learners (black), aligned by criterion session ( $>50 \%$ CRs; median \pm IQR). Bottom graphs, Bootstrapped sampling distributions of the medians (medians \pm IQRs). ${ }^{*}$ Significant differences between WT and FX distributions (KS tests with Bonferroni correction, CR rates: $p<0.005$; amplitude and timing: $p<0.006)$. In contrast to FX mice, CKO+PFC-Cre mice did not show deficits in these aspects of CR expression. $B$, Example behavioral sessions $2 \mathrm{~d}$ after meeting criterion for learners or the last day of training from nonlearners, from two representative CKO+PFC-Cre and CKO control mice (as described in Fig. 2). There is a similar performance for cK0 + PFC-Cre and control learners, including CR rate, amplitude, and timing, in contrast to FX mice. The results suggest that these aspects of CR expression are dependent on a brain region other than the PFC, in which FMRP remained intact.

the PFC of adult mice in which FMRP was absent throughout development (cON+PFC-Cre mice).

Similar to the previous experiment, immunohistochemistry indicated successful initiation of FMRP expression in the TECspecific region of PFC in $\mathrm{CON}$ mice (Fig. $5 A$ ). Analysis of $\mathrm{CR}$ rates during acquisition revealed no significant differences on any training day between $\mathrm{CON}+\mathrm{PFC}-\mathrm{Cre}$ mice and their WT littermates (which also received rAAV-Cre; $n=12, n=14$, K-S test: $d<0.70, p>0.0036$ for each time point; Fig. $5 B$ ). In contrast, $\mathrm{cON}+\mathrm{PFC}$-Cre mice showed significantly higher performance rates during training than their $\mathrm{CON}$ littermate controls (sham, no rAAV-Cre) beginning on day 9 of training $(n=12, n=10$, K-S test: $d>0.77, p<0.0036$ for each time point; Fig. $5 B$ ). Furthermore, analysis of learning onset indicated no delay between $\mathrm{CON}+$ PFC-Cre and WT+PFC-Cre mice (day 9 for both groups; one-tailed CI, $p<0.05$; Fig. $5 B$, bottom, green and black arrows), whereas cON-sham mice did not deviate from $0 \%$ CRs until the last day of training (day 14; one-tailed CI, $p<0.05$; Fig.
$5 B$, bottom, red arrow). In addition to the rescue of both group performance and delayed learning onset in $\mathrm{CON}+\mathrm{PFC}-\mathrm{Cre}$ mice to WT levels, the proportion of nonlearners was significantly decreased relative to $\mathrm{CON}$-sham controls and was not different from that observed for WT + PFC-Cre mice ( $17 \%$ of cON + PFCCre vs $60 \%$ of cON-sham, Fisher Exact test $=4.33, p=0.035$; $\mathrm{cON}+\mathrm{PFC}-\mathrm{Cre}$ vs $7 \%$ of WT + PFC-Cre $=0.57, p=0.45$; Fig. $5 C)$. The data show that, after initiation of FMRP production in the PFC of adult mice, both the higher proportion of nonlearners and the delay in learning onset were rescued to WT levels.

The previous experiment in which FMRP was knocked out in the adult PFC indicates that specific aspects of CR expression (performance rate, amplitude, and timing) are not impaired when FMRP is present in the rest of the brain. If the PFC indeed does not play a role in these aspects of CR expression, then those deficits should still be observed in $\mathrm{CON}+\mathrm{PFC}$-Cre mice, in which FMRP was restored only in the PFC and is deficient in the rest of the brain. This appears modestly true for performance rate $(n=$ 
A

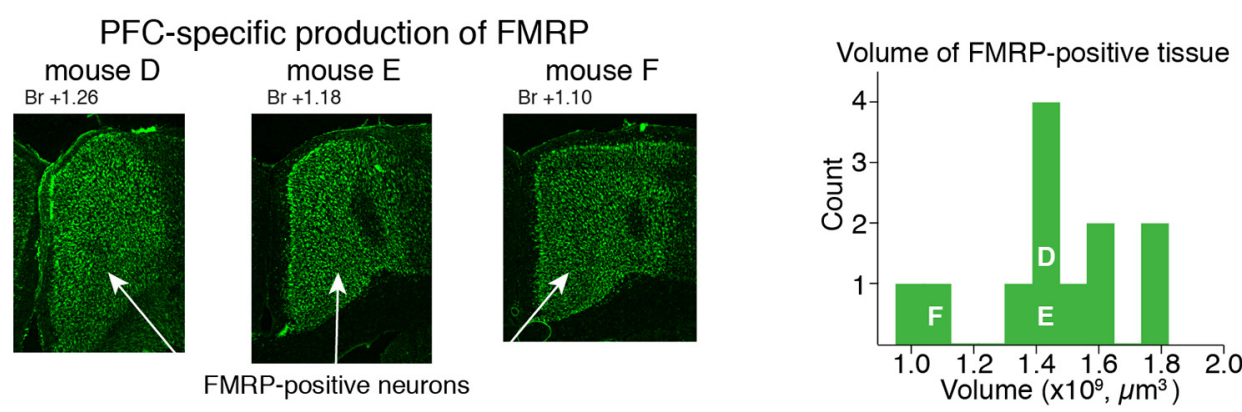

FMRP-positive tissue, $\mathrm{n}=12 \mathrm{cON}+\mathrm{PFC}$-Cre mice

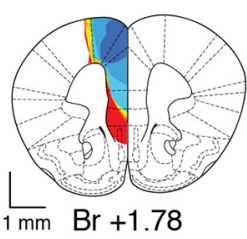

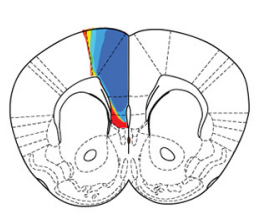

$\mathrm{Br}+1.42$

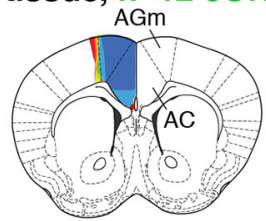

$\mathrm{Br}+1.18$

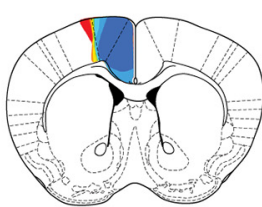

$\mathrm{Br}+0.98$

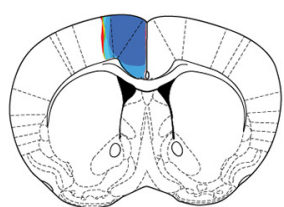

$\mathrm{Br}+0.74$

common areas 12

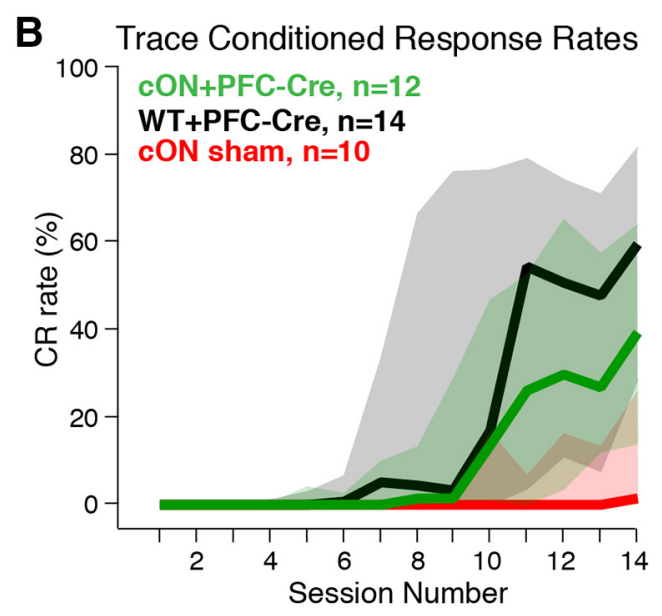

C Proportions of Learners and Non-Learners
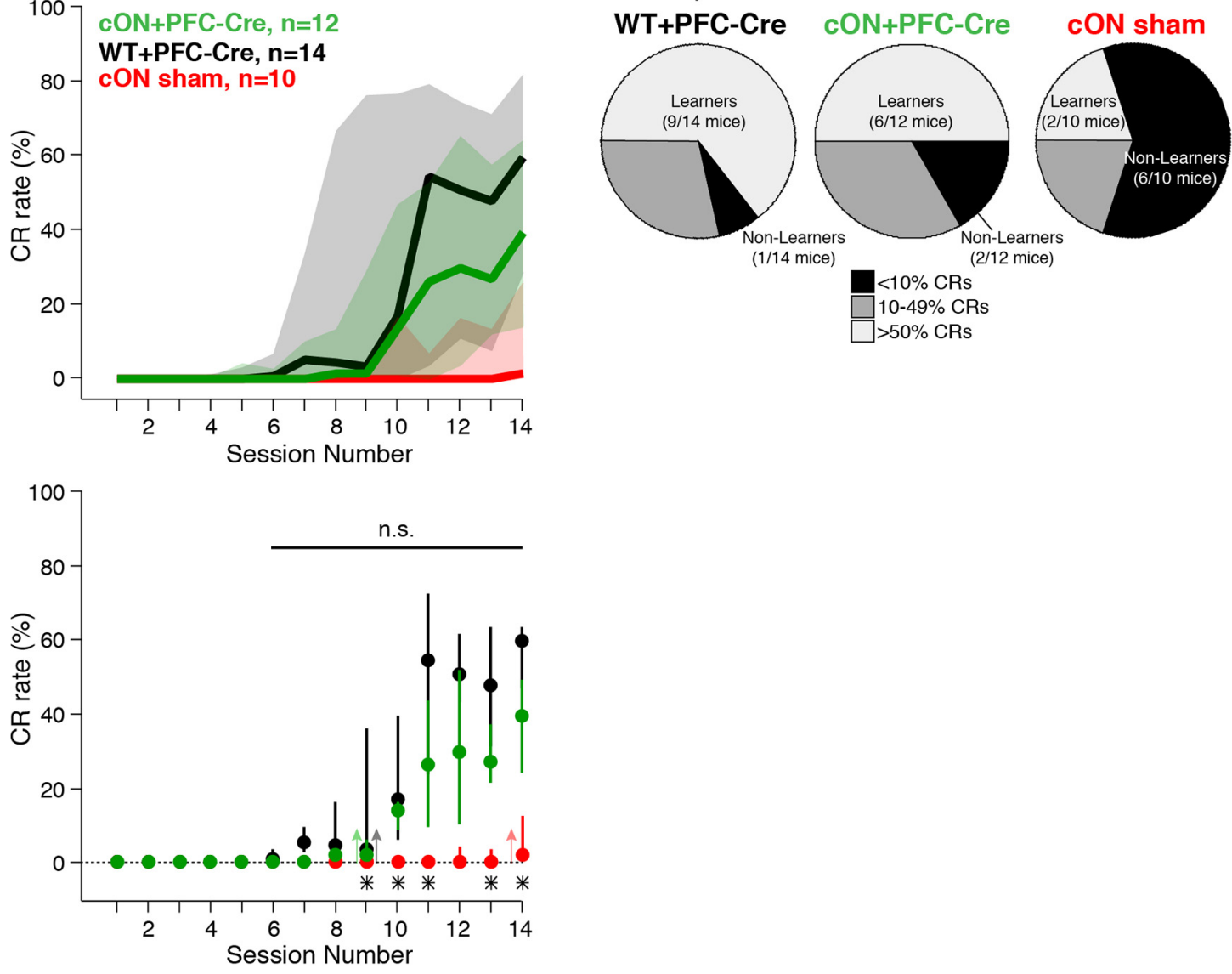

Figure 5. PFC-specific initiation of FMRP production in adult mice results in a rescue of PFC-associated deficits. $A$, FMRP immunohistochemistry from the PFC of 3 representative $C O N+P F C-C r e$ mice (left), with total volumes of FMRP-positive tissue for all mice shown on right (histogram, letters correspond to volumetric results from representative examples). Small dark regions within FMRP-positive tissue indicate some local tissue damage due to injections, also observed in control injected WT mice (data not shown). Areas of FMRP-positive tissue were reconstructed for all $\mathrm{CON}+\mathrm{PFC}-\mathrm{Cre}$ mice and showed considerable overlap in the medial agranular (AGm) and anterior cingulate (AC) regions of PFC previously shown to be critical for TEC. Bottom, Reverse color scale: dark blue represents regions where FMRP-positive tissue was observed for all 12 mice; warm colors represent regions where few mice overlapped. B, CR rates over $14 \mathrm{~d}$ of training for CON + PFC-Cre (green), WT+PFC-Cre (black), and CON-sham (red, top), and bootstrapped sampling distributions of the median (bottom, medians \pm IQRs). Sampling distributions were not different between $\mathrm{CON}+$ PFC-Cre and WT mice on any training day $(p>0.0036)$, while diverging from $\mathrm{CON}$-sham mice beginning day 9 (arrows, $p<0.0036)$. Similarly, CON + PFC-Cre and WT mice show the same learning onset (day 9, green and black arrows, 95th percentile (Is), whereas c0N-sham mice do not perform above " 0 " until day 14 (red arrow). *Significant differences between sampling distributions of CON+PFC-Cre and CON-sham mice on a given day of training (KS tests with Bonferroni correction, $p<0.0035$ ). C, CON + PFC-Cre and WT mice show a similar proportion of nonlearners (Fisher exact test, $p=0.45$ ), which was significantly lower than observed for c0N-sham mice $(p=0.035)$. 
A
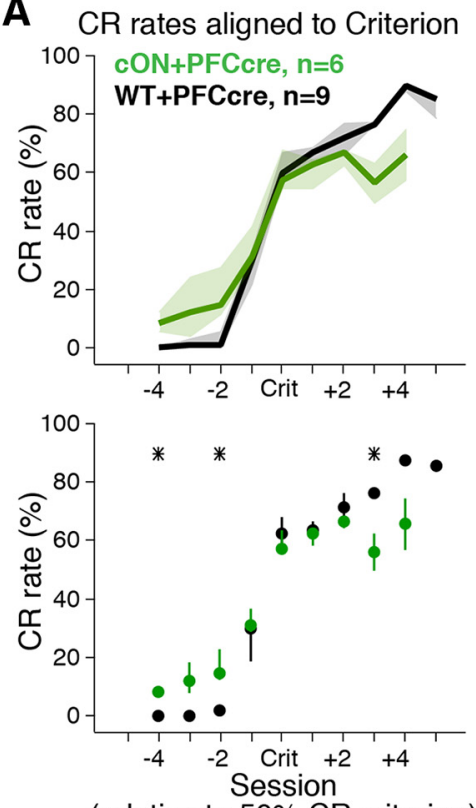

(relative to $50 \% \mathrm{CR}$ criterion)
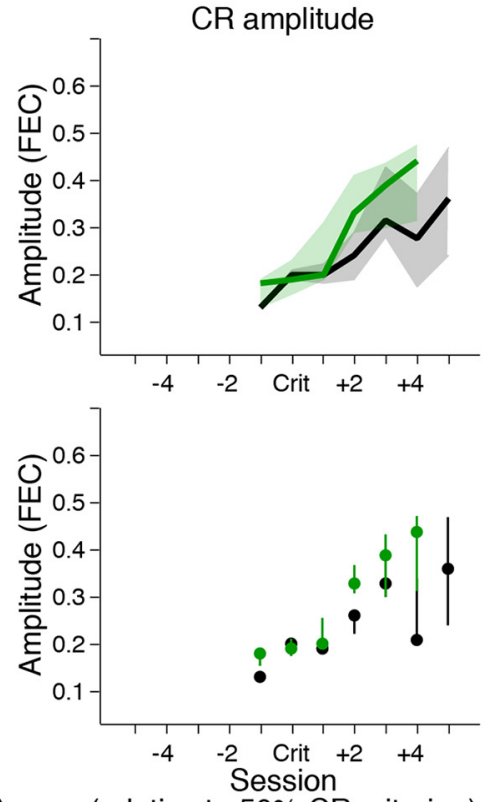

(relative to $50 \%$ CR criterion)

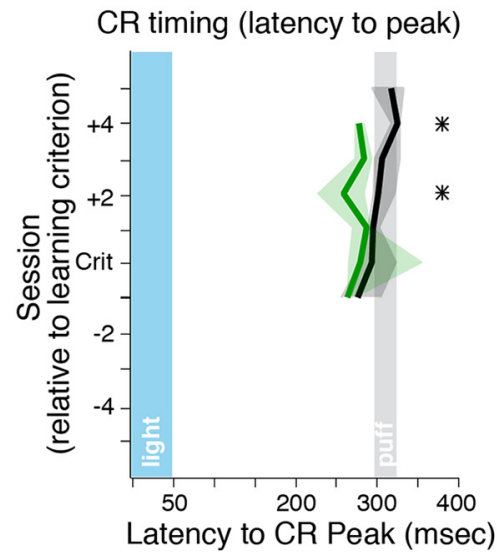

B

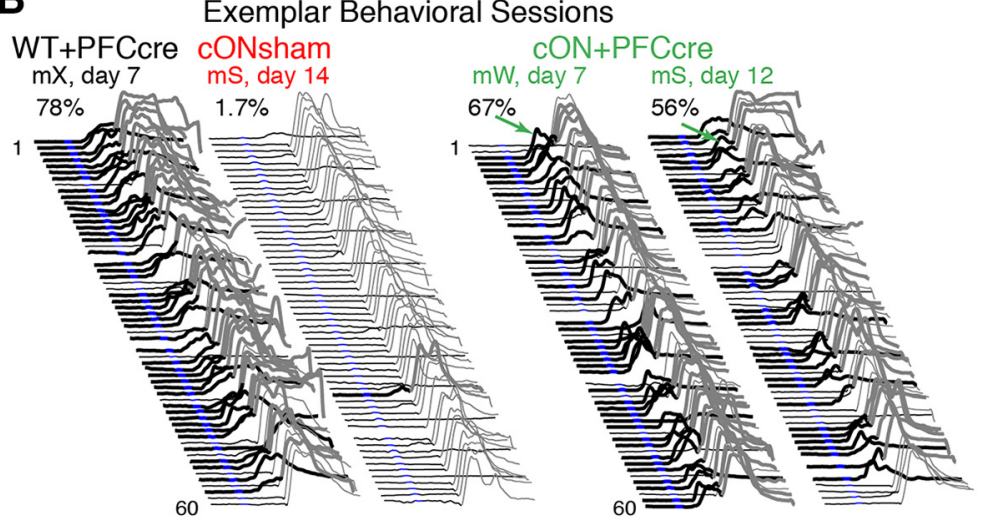

Figure 6. $\quad C O N+P F C-C r e$ and WT learners show deficits in performance rate and CR timing, whereas CR amplitude was rescued. $A$, CR rates (left), CR maximum amplitude (middle), and CR timing (latency to peak amplitude, right) in CON + PFC-Cre (green) and WT learners (black), aligned by criterion session ( $>50 \%$ CRs; median \pm IQR). Bottom graphs, Bootstrapped sampling distributions of the medians (medians \pm IQRs). * Significant differences between cON+PFC-Cre and WT distributions (KS tests with Bonferroni correction, CR rates: $p<0.005$; amplitude and timing: $p<0.007$ ).

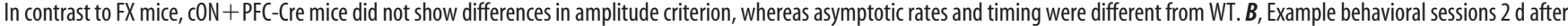
meeting criterion for learners or the last day of training from nonlearners, from two representative control and CON + PFC-Cre mice (as described in Fig. 2). There are lower performance rates and earlier timing (green arrows) for CON+PFC-Cre mice versus WT, whereas CR amplitudes were similar.

6, $n=9$, K-S test: $d>0.91, p<0.005$ for each time point; Fig. $6 A$, left) and timing (K-S test: $d>0.88, p<0.007$; Fig. $6 A$, right). However, the amplitude of CRs was not different from WT+PFC-Cre mice (K-S test: $d<0.88, p>0.007$; Fig. $6 A$, middle; behavioral examples shown in Fig. $6 B$ ), suggesting that the PFC can influence at least some aspects of learned motor responses when those motor regions are compromised.

\section{Discussion}

The most striking effect of conditional FMRP knock-out in the PFC was that a significant proportion of animals were unable to learn. Mice that were able to learn required at least 200 additional trials (3-6 sessions) to display learning relative to their WT littermates. In contrast, initiating FMRP production in the PFC resulted in a rescue of both the nonlearning phenotype and the delayed onset of learning. Remarkably, the rescue of PFCassociated deficits was achieved in the adult mouse after development. The results suggest that PFC dysfunction in FX is due, at least in part, to the continued function of FMRP in PFC neurons and cannot be entirely attributed to the absence of FMRP during development. Most importantly, the possibility of restoring PFC function in FX patients after development may be an achievable goal.

\section{PFC, TEC, and FX}

The necessity of the PFC for TEC has been established in several animal models (Kronforst-Collins and Disterhoft, 1998; Takehara et al., 2003; Kalmbach et al., 2009; Chen et al., 2014), including mice (Siegel et al., 2015). A functional PFC is required for both the acquisition and ongoing expression of eyeblink conditioning when the CS and US do not overlap in time (KronforstCollins and Disterhoft, 1998; Takehara et al., 2003; Kalmbach et al., 2009; Siegel et al., 2015). The motor expression of the learned eyelid response and its attributes (e.g., amplitude and timing) are driven by the cerebellum (Kalmbach et al., 2010; Kreider and Mauk, 2010; Siegel and Mauk, 2013; Heiney et al., 2014; Siegel et 
al., 2015; but see Ammann et al., 2016). The prevailing hypothesis is that a persistent PFC input to the cerebellum (via the pons) in response to the CS is required to bridge the temporal gap with the US (Weiss and Disterhoft, 2011; Siegel et al., 2012), and has been consistently observed in PFC recordings during TEC (TakeharaNishiuchi and Mcnaughton, 2008; Siegel et al., 2012; Siegel and Mauk, 2013; Hattori et al., 2014; Siegel, 2014, 2016). Based on this hypothesis, the trial structure of TEC is therefore similar to that used in working memory tasks, which in primates is thought to be supported by persistent responses in the PFC (Fuster and Alexander, 1971; Fuster, 1973; Goldman-Rakic, 1995). Working memory deficits have been reported in FX patients (Munir et al., 2000b; Cornish et al., 2009). As such, FX patients have difficulty in associating actions or events with consequences, particularly when events do not occur close in time. Although certainly a more complicated scenario for humans than the simplified TEC task used for our mice, it is possible that similar PFC processes are being probed in the current study. Trace fear conditioning also includes a stimulus-free interval separating the CS and footshock. Interestingly, that task has also been shown to be both PFCdependent and deficient in FX mice (Zhao et al., 2005).

Another hallmark of FX and other forms of autism is behavioral perseverance, in which patients repeat stereotyped behaviors even when the rule set has clearly changed (Wilding et al., 2002). Behavioral perseveration is associated with the striatum and can develop whether the PFC fails to inhibit striatal activity (Ridley, 1994; Menon et al., 2004). To date, no evidence for a striatal contribution to TEC has been demonstrated in mice, with the cerebellum shown to drive learned motor responses in eyeblink conditioning (Heiney et al., 2014; Siegel et al., 2015). In the current study, FX mice were able to efficiently extinguish their learned TEC responses when the US was removed, suggesting that circuits driving perseverating behaviors were likely not engaged by our task.

To our knowledge, FX patients have not been tested in TEC, but one prediction is that patients might show similar learning deficits to those observed in FX mice. Deficits in amplitude and performance for a non-PFC-dependent version of eyeblink conditioning have been reported for FX mice and human patients (Koekkoek et al., 2005). In the current study, FX mice showed similar deficits in performance, which appeared to be associated with FMRP status in the cerebellum (intact in $\mathrm{CKO}+\mathrm{PFC}-\mathrm{Cre}$ mice and deficient in FX and $\mathrm{CON}+\mathrm{PFC}-\mathrm{Cre}$ mice). However, rescue of FMRP in the PFC alone revealed a rescue of CR amplitude, suggesting that the PFC can influence some aspects of learned motor responses, even if the motor system itself is compromised. The latter finding suggests the possibility that rescue of function in a higher-order brain region, such as PFC, could have beneficial performance-related effects for FX patients.

\section{Brain region- and neuron-specific differences in FMRP function}

The absence of FMRP appears to affect neurons differently depending on brain region and neuronal subtype (Paluszkiewicz et al., 2011; Suvrathan and Chattarji, 2011; Brager et al., 2012; Routh et al., 2013; Vislay et al., 2013; Contractor et al., 2015; Kalmbach et al., 2015). PFC pyramidal tract projections to the pons are specifically implicated in TEC, as described above. In the pyramidal tract-projecting neurons of FX mice, the observed downregulation of $h$ channels would increase the likelihood of integrating asynchronous input to the dendrites into spike activity, and when coupled with functional alterations in K channels, show increased excitability in both the dendritic and somatic compartments (Kalmbach et al., 2015). The result would be a noisy integration of both CS and random non-CS inputs during larger (asynchronous) time windows for a given training trial, and variable response patterns across training. FMRP also binds directly to BK channels and, if absent, leads to increased neurotransmitter release onto downstream neurons (Deng et al., 2013). The cumulative effects of FMRP absence in PFC pyramidal tract-projecting neurons would therefore culminate in an amplified, inconsistent input to the cerebellum across training trials, resulting in delayed or deterred motor learning. The successful rescue of function after restoring FMRP in the current study suggests that the regulation of some of these channels is ongoing in the adult PFC.

Similar to excitatory cells, alterations in inhibitory function also show brain region- and subclass-specific dysregulation (Selby et al., 2007; Gibson et al., 2008; Paluszkiewicz et al., 2011; Suvrathan and Chattarji, 2011). Inhibitory responses in excitatory cells have been investigated in FX mice, but the expression of FMRP and potential neuronal dysfunction in interneurons has not been directly tested. The current findings, however, provide an opportunity to begin addressing cell type-specific contributions to PFC dysfunction in FX, for example, by using cell type-specific knock-out/restoration of FMRP and/or single-cell recordings to investigate cell-type responses during training.

In addition to potential cell type-specific differences in dysfunction, differences in synaptic plasticity resulting from the absence of FMRP have also been noted between brain regions (Huber et al., 2002; Li et al., 2002; Suvrathan et al., 2010; Krueger et al., 2011; Brager et al., 2012). It is no surprise then that, although a given therapeutic intervention may rescue function in one cell type or brain region, it may fail or even exacerbate dysfunction in another (e.g., Suvrathan et al., 2010; Suvrathan and Chattarii, 2011). TEC engages a network of brain regions to support learning. In addition to PFC, the hippocampus, amygdala, and cerebellum also support TEC (Takehara et al., 2003; Tseng et al., 2004; Siegel et al., 2015). Using region-specific manipulations of FMRP, we were able to tease apart which behavioral deficits could be attributed to PFC dysfunction and which may be due to dysfunction in other brain regions. Given the sensitivity of TEC to PFC disruption in the mouse, this paradigm may be useful for screening potential therapeutics for PFC-dependent behaviors. Similar manipulations to those used here could also be used to target other brain regions, such as the hippocampus or amygdala, to determine whether behavioral deficits associated with those brain regions can be rescued in the adult.

\section{The continuing role of FMRP after development}

FX is generally considered a developmental disorder with lifelong impact. Indeed, several studies revealed developmental dysregulation of neurons in FX mice, and recent efforts to rescue developmental dysregulation have generated much excitement (Dölen et al., 2007; Michalon et al., 2012; Dolan et al., 2013). However, data also support ongoing functional roles for FMRP in neurons that include lifelong regulation of protein expression (e.g., the expression of ion channels) as well as protein-protein interactions in adult neurons (e.g., in regulating $\mathrm{BK}$ and $\mathrm{K}_{\mathrm{Na}}$ channels) (Brown et al., 2010; Deng et al., 2013). It has been difficult to dissociate the relative contributions of FMRP loss during development and the continuous absence of FMRP during adulthood to the autistic phenotype. Interventions to repair developmental dysfunction, although certainly necessary and worthwhile endeavors, may not alone cure the disease. We used region-specific manipulations of FMRP production and found that the PFC- 
associated deficits observed in FX mice could be induced in the adult brain, and could be rescued when endogenous FMRP production was restored in PFC neurons after development. The data suggest that, at least for PFC, dysfunction may be due to the continuing absence of FMRP in the adult brain (Dolan et al., 2013). More importantly, the results suggest that PFC function could potentially be restored in adult FX patients.

\section{References}

Ammann C, Márquez-Ruiz J, Gómez-Climent MÁ, Delgado-García JM, Gruart A (2016) The motor cortex is involved in the generation of classically conditioned eyelid responses in behaving rabbits. J Neurosci 36:69887001. CrossRef Medline

Bernardet M, Crusio WE (2006) Fmr1 KO mice as a possible model of autistic features. Sci World J 6:1164-1176. CrossRef Medline

Borghuis BG, Tian L, Xu Y, Nikonov SS, Vardi N, Zemelman BV, Looger LL (2011) Imaging light responses of targeted neuron populations in the rodent retina. J Neurosci 31:2855-2867. CrossRef Medline

Brager DH, Johnston D (2014) Channelopathies and dendritic dysfunction in fragile X syndrome. Brain Res Bull 103:11-17. CrossRef Medline

Brager DH, Akhavan AR, Johnston D (2012) Impaired dendritic expression and plasticity of h-channels in the fmrl(-/y) mouse model of fragile $\mathrm{X}$ syndrome. Cell Rep 1:225-233. CrossRef Medline

Bray S, Hirt M, Jo B, Hall SS, Lightbody AA, Walter E, Chen K, Patnaik S, Reiss AL (2011) Aberrant frontal lobe maturation in adolescents with fragile $\mathrm{X}$ syndrome is related to delayed cognitive maturation. Biol Psychiatry 70:852-858. CrossRef Medline

Brown MR, Kronengold J, Gazula VR, Chen Y, Strumbos JG, Sigworth FJ, Navaratnam D, Kaczmarek LK (2010) Brief communications. Nat Neurosci 13:819-821. CrossRef Medline

Brown V, Jin P, Ceman S, Darnell JC, O'Donnell WT, Tenenbaum SA, Jin X, Feng Y, Wilkinson KD, Keene JD, Darnell RB, Warren ST (2001) Microarray identification of FMRP-associated brain mRNAs and altered mRNA translational profiles in fragile X syndrome. Cell 107:477-487. CrossRef Medline

Chen H, Yang L, Xu Y, Wu GY, Yao J, Zhang J, Zhu ZR, Hu ZA, Sui JF, Hu B (2014) Prefrontal control of cerebellum-dependent associative motor learning. Cerebellum 13:64-78. CrossRef Medline

Coffee B, Keith K, Albizua I, Malone T, Mowrey J, Sherman SL, Warren ST (2009) Incidence of Fragile X Syndrome by newborn screening for methylated FMR1 DNA. Am J Hum Genet 85:503-514. CrossRef Medline

Contractor A, Klyachko VA, Portera-Cailliau C (2015) Altered neuronal and circuit excitability in Fragile X syndrome. Neuron 87:699-715. CrossRef Medline

Cornish KM, Kogan CS, Li L, Turk J, Jacquemont S, Hagerman RJ (2009) Lifespan changes in working memory in fragile $\mathrm{X}$ premutation males. Brain Cogn 69:551-558. CrossRef Medline

Darnell JC, Jensen KB, Jin P, Brown V, Warren ST, Darnell RB (2001) Fragile $\mathrm{X}$ mental retardation protein targets $\mathrm{G}$ quartet mRNAs important for neuronal function. Cell 107:489-499. CrossRef Medline

Darnell JC, Van Driesche SJ, Zhang C, Hung KY, Mele A, Fraser CE, Stone EF, Chen C, Fak JJ, Chi SW, Licatalosi DD, Richter JD, Darnell RB (2011) FMRP stalls ribosomal translocation on mRNAs linked to synaptic function and autism. Cell 146:247-261. CrossRef Medline

Deng PY, Rotman Z, Blundon JA, Cho Y, Cui J, Cavalli V, Zakharenko SS, Klyachko VA (2013) FMRP regulates neurotransmitter release and synaptic information transmission by modulating action potential duration via BK channels. Neuron 77:696-711. CrossRef Medline

Dolan BM, Duron SG, Campbell DA, Vollrath B, Shankaranarayana Rao BS, Ko HY, Lin GG, Govindarajan A, Choi SY, Tonegawa S (2013) Rescue of fragile X syndrome phenotypes in Fmr1 KO mice by the small-molecule PAK inhibitor FRAX486. Proc Natl Acad Sci U S A 110:5671-5676. CrossRef Medline

Dölen G, Osterweil E, Rao BS, Smith GB, Auerbach BD, Chattarji S, Bear MF (2007) Correction of fragile X syndrome in mice. Neuron 56:955-962. CrossRef Medline

Fuster JM (1973) Unit activity in prefrontal cortex during delayed-response performance: neuronal correlates of transient memory. J Neurophysiol 36:61-78. Medline

Fuster JM, Alexander GE (1971) Neuron activity related to short-term memory. Science 173:652-654. CrossRef Medline
Gibson JR, Bartley AF, Hays SA, Huber KM (2008) Imbalance of neocortical excitation and inhibition and altered UP states reflect network hyperexcitability in the mouse model of fragile X syndrome. J Neurophysiol 100: 2615-2626. CrossRef Medline

Goldman-Rakic PS (1995) Cellular basis of working memory. Neuron 14: 477-485. CrossRef Medline

Guo W, Allan AM, Zong R, Zhang L, Johnson EB, Schaller EG, Murthy AC, Goggin SL, Eisch AJ, Ben A Oostra BA, Nelson DL, Jin P, Zhao X (2011) Ablation of Fmrp in adult neural stem cells disrupts hippocampusdependent learning. Nat Med 17:559-565. CrossRef Medline

Hattori S, Yoon T, Disterhoft JF, Weiss C (2014) Functional reorganization of a prefrontal cortical network mediating consolidation of trace eyeblink conditioning. J Neurosci 34:1432-1445. CrossRef Medline

He Q, Nomura T, Xu J, Contractor A (2014) The developmental switch in GABA polarity is delayed in fragile X mice. J Neurosci 34:446-450. CrossRef Medline

Heiney SA, Wohl MP, Chettih SN, Ruffolo LI, Medina JF (2014) Cerebellardependent expression of motor learning during eyeblink conditioning in head-fixed mice. J Neurosci 34:14845-14853. CrossRef Medline

Huber KM, Gallagher SM, Warren ST, Bear MF (2002) Altered synaptic plasticity in a mouse model of fragile X mental retardation. Proc Natl Acad Sci U S A 99:7746-7750. CrossRef Medline

Kalmbach BE, Ohyama T, Kreider JC, Riusech F, Mauk MD (2009) Interactions between prefrontal cortex and cerebellum revealed by trace eyelid conditioning. Learn Mem 16:86-95. CrossRef Medline

Kalmbach BE, Davis T, Ohyama T, Riusech F, Nores WL, Mauk MD (2010) Cerebellar cortex contributions to the expression and timing of conditioned eyelid responses. J Neurophysiol 103:2039-2049. CrossRef Medline

Kalmbach BE, Johnston D, Brager DH (2015) Cell-type specific channelopathies in the prefrontal cortex of the fmr1-/y mouse model of Fragile $X$ Syndrome. eNeuro 2:1-21. CrossRef Medline

Koekkoek SK, Yamaguchi K, Milojkovic BA, Dortland BR, Ruigrok TJ, Maex R, De Graaf W, Smit AE, VanderWerf F, Bakker CE, Willemsen R, Ikeda T, Kakizawa S, Onodera K, Nelson DL, Mientjes E, Joosten M, De Schutter E, Oostra BA, Ito M, et al. (2005) Deletion of FMR1 in Purkinje cells enhances parallel fiber LTD, enlarges spines, and attenuates cerebellar eyelid conditioning in Fragile X syndrome. Neuron 47:339-352. CrossRef Medline

Kramvis I, Mansvelder HD, Loos M, Meredith R (2013) Hyperactivity, perseveration and increased responding during attentional rule acquisition in the Fragile X mouse model. Front Behav Neurosci 7:172. CrossRef Medline

Kreider JC, Mauk MD (2010) Eyelid conditioning to a target amplitude: adding how much to whether and when. J Neurosci 30:14145-14152. CrossRef Medline

Kronforst-Collins MA, Disterhoft JF (1998) Lesions of the caudal area of rabbit medial prefrontal cortex impair trace eyeblink conditioning. Neurobiol Learn Mem 69:147-162. CrossRef Medline

Krueger DD, Osterweil EK, Chen SP, Tye LD, Bear MF (2011) Cognitive dysfunction and prefrontal synaptic abnormalities in a mouse model of fragile X syndrome. Proc Natl Acad Sci U S A 108:2587-2592. CrossRef Medline

Kulesa A, Krzywinski M, Blainey P, Altman N (2015) Sampling distributions and the bootstrap. Nat Methods 12:477-478. CrossRef Medline

Li J, Pelletier MR, Perez Velazquez JL, Carlen PL (2002) Reduced cortical synaptic plasticity and GluR1 expression associated with fragile X mental retardation protein deficiency. Mol Cell Neurosci 19:138-151. CrossRef Medline

Martin BS, Huntsman MM (2012) Pathological plasticity in fragile X syndrome. Neural Plast 2012:275630. CrossRef Medline

Menon V, Leroux J, White CD, Reiss AL (2004) Frontostriatal deficits in fragile X syndrome: relation to FMR1 gene exression. Proc Natl Acad Sci U S A 101:3615-3620. CrossRef Medline

Michalon A, Sidorov M, Ballard TM, Ozmen L, Spooren W, Wettstein JG, Jaeschke G, Bear MF, Lindemann L (2012) Chronic pharmacological mGlu5 inhibition corrects fragile $\mathrm{X}$ in adult mice. Neuron 74:49-56. CrossRef Medline

Mientjes EJ, Nieuwenhuizen I, Kirkpatrick L, Zu T, Hoogeveen-Westerveld M, Severijnen L, Rifé M, Willemsen R, Nelson DL, Oostra BA (2006) The generation of a conditional Fmr1 knock out mouse model to study Fmrp function in vivo. Neurobiol Dis 21:549-555. CrossRef Medline Mineur YS, Sluyter F, de Wit S, Oostra BA, Crusio WE (2002) Behavioral 
and neuroanatomical characterization of the Fmr1 knockout mouse. Hippocampus 12:39-46. CrossRef Medline

Munir F, Cornish KM, Wilding J (2000a) A neuropsychological profile of attention deficits in young males with fragile $\mathrm{X}$ syndrome. Neuropsychologia 38:1261-1270. CrossRef Medline

Munir F, Cornish KM, Wilding J (2000b) Nature of the working memory deficit in fragile-X syndrome. Brain Cogn 44:387-401. CrossRef Medline

Osterweil EK, Krueger DD, Reinhold K, Bear MF (2010) Hypersensitivity to mGluR5 and ERK1/2 leads to excessive protein synthesis in the hippocampus of a mouse model of fragile X syndrome. J Neurosci 30:1561615627. CrossRef Medline

Paluszkiewicz SM, Olmos-Serrano JL, Corbin JG, Huntsman MM (2011) Impaired inhibitory control of cortical synchronization in fragile $\mathrm{X}$ syndrome. J Neurophysiol 106:2264-2272. CrossRef Medline

Pieretti M, Zhang FP, Fu YH, Warren ST, Oostra BA, Caskey CT, Nelson DL (1991) Absence of expression of the FMR-1 gene in fragile X syndrome. Cell 66:817-822. CrossRef Medline

Ramos A, Hollingworth D, Adinolfi S, Castets M, Kelly G, Frenkiel TA, Bardoni B, Pastore A (2006) The structure of the N-terminal domain of the Fragile X Mental Retardation protein: a platform for protein-protein interaction. Structure 14:21-31. CrossRef Medline

Ridley RM (1994) The psychology of perseverative and stereotyped behaviour. Prog Neurobiol 44:221-231. CrossRef Medline

Routh BN, Johnston D, Brager DH (2013) Loss of functional A-type potassium channels in the dendrites of CA1 pyramidal neurons from a mouse model of fragile X syndrome. J Neurosci 33:19442-19450. CrossRef Medline

Schindelin J, Arganda-Carreras I, Frise E, Kaynig V, Longair M, Pietzsch T, Preibisch S, Rueden C, Saalfeld S, Schmid B, Tinevez JY, White DJ, Hartenstein V, Eliceiri K, Tomancak P, Cardona A (2012) Fiji: an opensource plat- form for biological-image analysis. Nat Methods 9:676-682. CrossRef Medline

Selby L, Zhang C, Sun QQ (2007) Major defects in neocortical GABAergic inhibitory circuits in mice lacking the fragile $\mathrm{X}$ mental retardation protein. Neurosci Lett 412:227-232. CrossRef Medline

Siegel JJ (2014) Modification of persistent responses in medial prefrontal cortex during learning in trace eyeblink conditioning. J Neurophysiol 112:2123-2137. CrossRef Medline

Siegel JJ (2016) Prefrontal single-neuron responses after changes in task contingencies during trace eyeblink conditioning in rabbits. eNeuro 3:ENEURO. CrossRef Medline

Siegel JJ, Mauk MD (2013) Persistent activity in prefrontal cortex during trace eyelid conditioning: dissociating responses that reflect cerebellar output from those that do not. J Neurosci 33:15272-15284. CrossRef Medline

Siegel JJ, Kalmbach B, Chitwood RA, Mauk MD (2012) Persistent activity in a cortical-to-subcortical circuit: bridging the temporal gap in trace eyelid conditioning. J Neurophysiol 107:50-64. CrossRef Medline
Siegel JJ, Taylor W, Gray R, Kalmbach B, Zemelman BV, Desai NS, Johnston D, Chitwood RA (2015) Trace eyeblink conditioning in mice is dependent upon the dorsal medial prefrontal cortex, cerebellum, and amygdala: behavioral characterization and functional circuitry. eNeuro 2:1-29. CrossRef Medline

Suvrathan A, Chattarji S (2011) Fragile X syndrome and the amygdala. Curr Opin Neurobiol 21:509-515. CrossRef Medline

Suvrathan A, Hoeffer CA, Wong H, Klann E, Chattarji S (2010) Characterization and reversal of synaptic defects in the amygdala in a mouse model of fragile X syndrome. Proc Natl Acad Sci U S A 107:1159111596. CrossRef Medline

Takehara K, Kawahara S, Kirino Y (2003) Time-dependent reorganization of the brain components underlying memory retention in trace eyeblink conditioning. J Neurosci 23:9897-9905. Medline

Takehara-Nishiuchi K, McNaughton BL (2008) Spontaneous changes of neocortical code for associative memory during consolidation. Science 322:960-963. CrossRef Medline

Tseng W, Guan R, Disterhoft JF, Weiss C (2004) Trace eyeblink conditioning is hippocampally dependent in mice. Hippocampus 14:58-65. CrossRef Medline

Verheij C, Bakker CE, de Graaff E, Keulemans J, Willemsen R, Verkerk AJ, Galjaard H, Reuser AJ, Hoogeveen AT, Oostra BA (1993) Characterization and localization of the FMR-1 gene product associated with fragile $\mathrm{X}$ syndrome. Nature 363:722-724. CrossRef Medline

Vislay RL, Martin BS, Olmos-Serrano JL, Kratovac S, Nelson DL, Corbin JG, Huntsman MM (2013) Homeostatic responses fail to correct defective amygdala inhibitory circuit maturation in Fragile X syndrome. J Neurosci 33:7548-7558. CrossRef Medline

Wahlstrom-Helgren S, Klyachko VA (2015) $\mathrm{GABA}_{\mathrm{B}}$ receptor-mediated feed-forward circuit dysfunction in the mouse model of fragile $\mathrm{x}$ syndrome. J Physiol 593 22:5009-5024. CrossRef Medline

Weiss C, Disterhoft JF (2011) Exploring prefrontal cortical memory mechanisms with eyeblink conditioning. Behav Neurosci 125:318-326. CrossRef Medline

Wilding J, Cornish K, Munir F (2002) Further delineation of the executive deficit in males with fragile-X syndrome. Neuropsychologia 40:13431349. CrossRef Medline

Yan QJ, Asafo-Adjei PK, Arnold HM, Brown RE, Bauchwitz RP (2004) A phenotypic and molecular characterization of the fmr1-tm1Cgr Fragile X mouse. Genes Brain Behav 3:337-359. CrossRef Medline

Zhang Y, Brown MR, Hyland C, Chen Y, Kronengold J, Fleming MR, Kohn AB, Moroz LL, Kaczmarek LK (2012) Regulation of neuronal excitability by interaction of Fragile X Mental Retardation protein with slack potassium channels. J Neurosci 32:15318-15327. CrossRef Medline

Zhao MG, Toyoda H, Ko SW, Ding HK, Wu LJ, Zhuo M (2005) Deficits in trace fear memory and long-term potentiation in a mouse model for Fragile X Syndrome. J Neurosci 25:7385-7392. CrossRef Medline 